\title{
Muscle structure, sarcomere length and influences on meat quality : A review
}

\section{Ertbjerg, Per}

\author{
2017-10
}

Ertbjerg , P \& Puolanne , E 2017 , ' Muscle structure, sarcomere length and influences on meat quality : A review ' , Meat Science , vol. 132 , pp. 139-152 . https://doi.org/10.1016/j.meatsci.2017.04.261

http://hdl.handle.net/10138/308940

https://doi.org/10.1016/j.meatsci.2017.04.261

cc_by_nc_nd

acceptedVersion

Downloaded from Helda, University of Helsinki institutional repository.

This is an electronic reprint of the original article.

This reprint may differ from the original in pagination and typographic detail.

Please cite the original version. 


\title{
Muscle structure, sarcomere length and influences on meat quality: A review Per Ertbjerg \& Eero Puolanne
}

Department of Food and Environmental Sciences, University of Helsinki, PO Box 66, FI00014, Helsinki, Finland

\begin{abstract}
The basic contractile unit of muscle, the sarcomere, will contract as the muscle goes into rigor post-mortem. Depending on the conditions, such as the rate of $\mathrm{pH}$ decline, the cooling rate and the mechanical restraints on the muscles, this longitudinal shortening will result in various post-mortem sarcomere lengths as well as lateral differences in the distances between the myosin and actin filaments. This shortening is underlying the phenomena described as rigor contraction, thaw rigor, cold shortening and heat shortening. The shortening in combination with the molecular architecture of the sarcomere as defined by the myosin filaments and their S-1 and S-2 units, the interaction with the actin filaments, and the boundaries formed by the Z-disks will subsequently influence basic meat quality traits including tenderness and water-holding capacity. Biochemical reactions from proteolysis and glycogen metabolism interrelate with the sarcomere length in a complex manner. The sarcomere length is also influencing the eating quality of cooked meat and the water-holding in meat products.
\end{abstract}

Keywords: Rigor contraction, thaw rigor, cold shortening, heat shortening, tenderness, waterholding

\section{Contents}

1. Introduction

2. Structural aspects

2.1. Myosin filaments

2.2. Actin filaments

2.3. Titin, nebulin and obscurin

2.4. The Z-disk

2.5. The M-band

2.6. Sarcomere structure in shortening

2.7. Sarcomere length in living muscle

3. Postmortem muscle contraction

3.1. Rigor mortis 


\subsection{Thaw rigor}

3.3. Cold shortening

3.4. Heat shortening

4. Biophysical aspects

4.1. Tenderness

4.2. Water-holding capacity in raw meat

5. Biochemical aspects

5.1. Proteolysis

5.2. Glycogen metabolism

6. Technological aspects

6.1. Prevention of sarcomere shortening

6.2. Cooking

6.3. Water-holding capacity in meat products

7. Conclusions

References

\section{Introduction}

Sarcomeres are the smallest contractile units and serve as the basic force-producing machinery of striated muscles (Fig. 1). In a living muscle, the sarcomeres fulfill their locomotive tasks, and as a by-product, they also produce a major part of the body heat. The average sarcomere resting lengths are controlled dynamically through the necessary number of sarcomeres in each muscle, so that the movement ranges required can be obtained within the contractibility of the sarcomeres $( \pm 40 \%)$. Then the position of joints dictates at any given moment the actual length of sarcomeres which may vary even within a muscle. The sarcomere lengths, while an animal is living, have only indirect effects on meat quality, but soon postmortem there will be relevant changes: the position of joints, the rate of postmortem reactions, due to the perimortal circumstances, like nutritive status, stress, postmortem temperature etc. The postmortal sarcomere lengths have marked effects on textural properties of raw and cooked meat, and on water-holding especially in raw meat as well as indirect effects on color, taste etc. This review makes an attempt to cover the most important aspects of the various effects of the postmortem variation of sarcomere lengths in meat on meat quality. 


\section{Structural aspects of the sarcomere}

Sarcomeres are renewed continuously during muscle growth and physiological turnover and are assembled from an immense number of protein subunits into a very large and most regular macromolecular complex. The structure of the sarcomere is thus very interconnected and at the same time extremely ordered. Myofibrils have a characteristic striated appearance which is readily observable by light microscopy as alternating light and dark bands. This is a result of the precise alignment of the filaments in the sarcomere. The light band is termed the I-band and the dark band is known as the A-band. The central region of the A-band is termed the $\mathrm{H}$-zone, and in the center of this is the M-band. The motor protein myosin is organized into thick filaments in the A-band. Actin monomers are assembled into thin filaments that span the I-band and overlap with thick filaments in the A-band. The Z-disks form the lateral boundaries of the sarcomere where the thin filaments are anchored (Fig. 1).
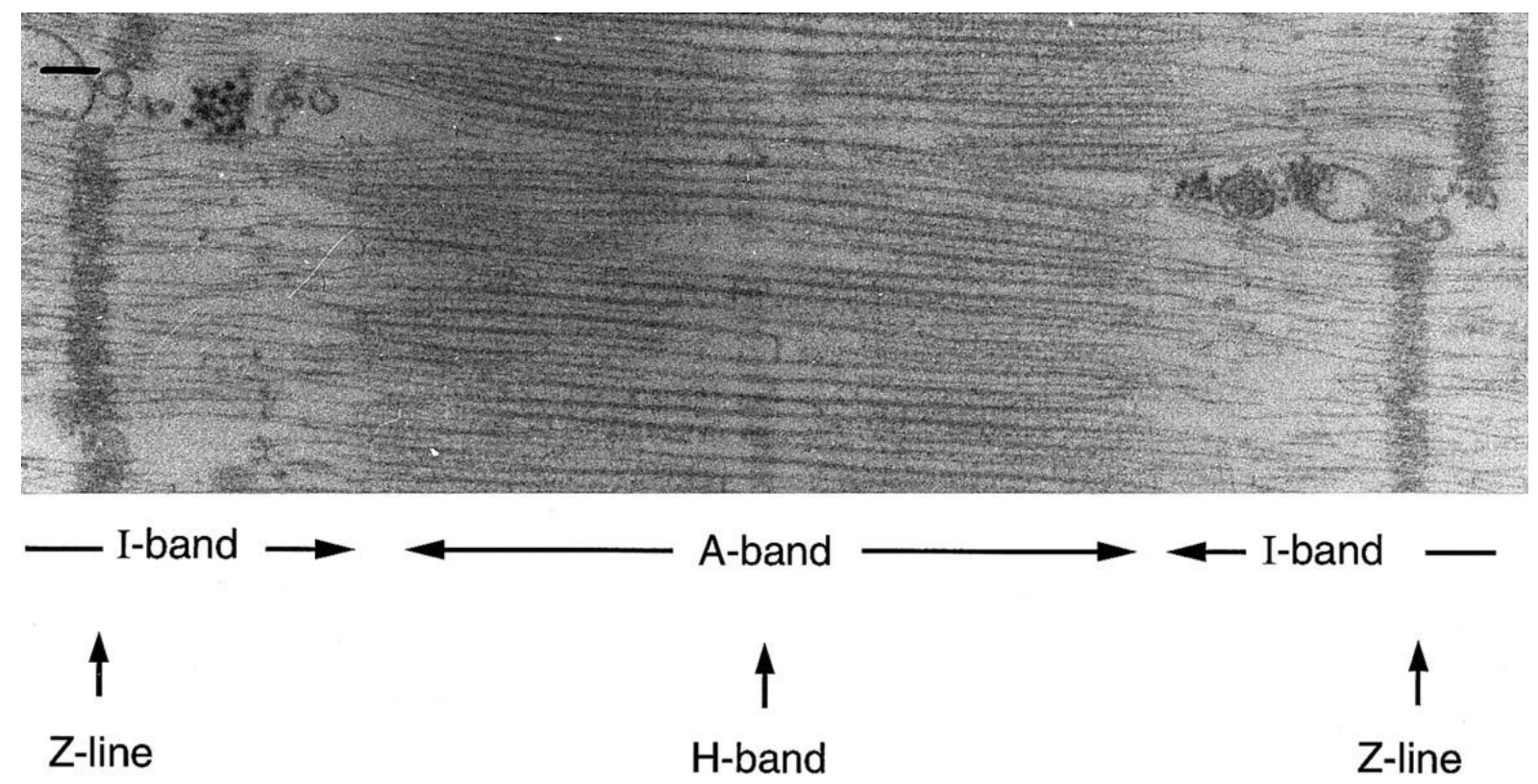

Fig. 1. Electron micrograph of a longitudinal section of a sarcomere from rabbit psoas muscle. The A-band, I-band, H-band and Z-line is indicated. Scale bar (upper left), $100 \mathrm{~nm}$. From Millman (1998).

\subsection{Myosin filaments}

Myosin filaments (or thick filaments) are organized in a hexagonal lattice 40 to $45 \mathrm{~nm}$ apart, with the actin filaments in between them (Huxley, 1969). Each myosin filament is surrounded by six actin filaments in the overlap region at both ends whereas each actin filament has three neighboring myosin filaments (Fig. 2). Myosin filaments within the sarcomere have a highly uniform length of about 1.5 to $1.6 \mu \mathrm{m}$, a backbone diameter of 13 to $18 \mathrm{~nm}$ and appear to 
contain a small hollow core with a diameter of 3 to $5 \mathrm{~nm}$ (Squire, Cantino, Chew, Denny, Harford, Hudson, \& Luther, 1998; Miroshnichenko, Balanuk, \& Nozdrenko, 2000). Projections (S-1 + S-2 fragments) occur at regular intervals along the filaments. Myosin filaments are comprised of 250-300 myosin molecules (Fig. 3) and some associated proteins. Muscle myosin is a large molecule with a molecular weight of $520 \mathrm{kDa}$ and is made of six polypeptide chains, consisting of two identical heavy chains of $220 \mathrm{kDa}$ and two pairs of light chains around 20 $\mathrm{kDa}$. The myosin molecule is often divided into two functional units referred to as the head and the rod. The amino-terminal ends of the heavy chains form the globular heads (the S-1 fragment) which each has two associated light chains. The rod is formed by the twisted $\alpha$ helical region of the two heavy chains, and the C-terminal portion of the rod is called light meromyosin and the other part S-2. The heads of the myosin molecules (S-1) stretch out from the core of the thick filaments and interact with the thin filaments in a repeated pattern. The central region of the myosin filament, without the projections, is 0.15 to $0.20 \mu \mathrm{m}$ in length (Huxley, 1963) and is also known as the bare zone. It contains only myosin rods and is anchored and aligned in the $\mathrm{M}$-line. Other proteins identified as components of the myosin filament include myosin binding proteins $\mathrm{C}$ and $\mathrm{H}$.

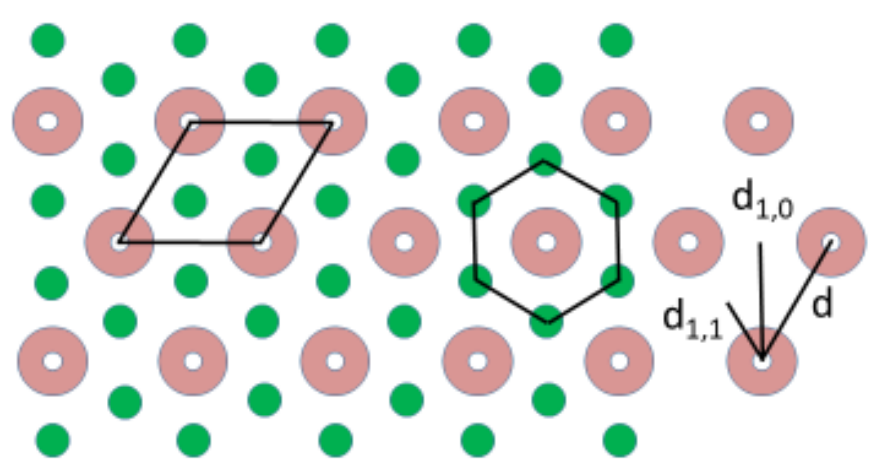

Fig. 2. Diagram of the filament lattice of mammalian striated muscle in the region of the sarcomere with overlap of myosin (large blue circles) and actin (small red circles) filaments. The diagram depicts the cross section of a unit cell at in the A-band by connection of 4 myosin filaments (rhombus) and also by connection of 6 actin filaments (hexagon). $A$ unit cell is the repeating unit of a myofibril meaning the above cross-sectional area, and the length of the sarcomere length. The distance between myosin filaments (d) along with the lattice plane distances $\left(d_{1,0}\right.$ and $\left.d_{1,1}\right)$ obtained from $X$-ray diffraction measurements are also shown. 


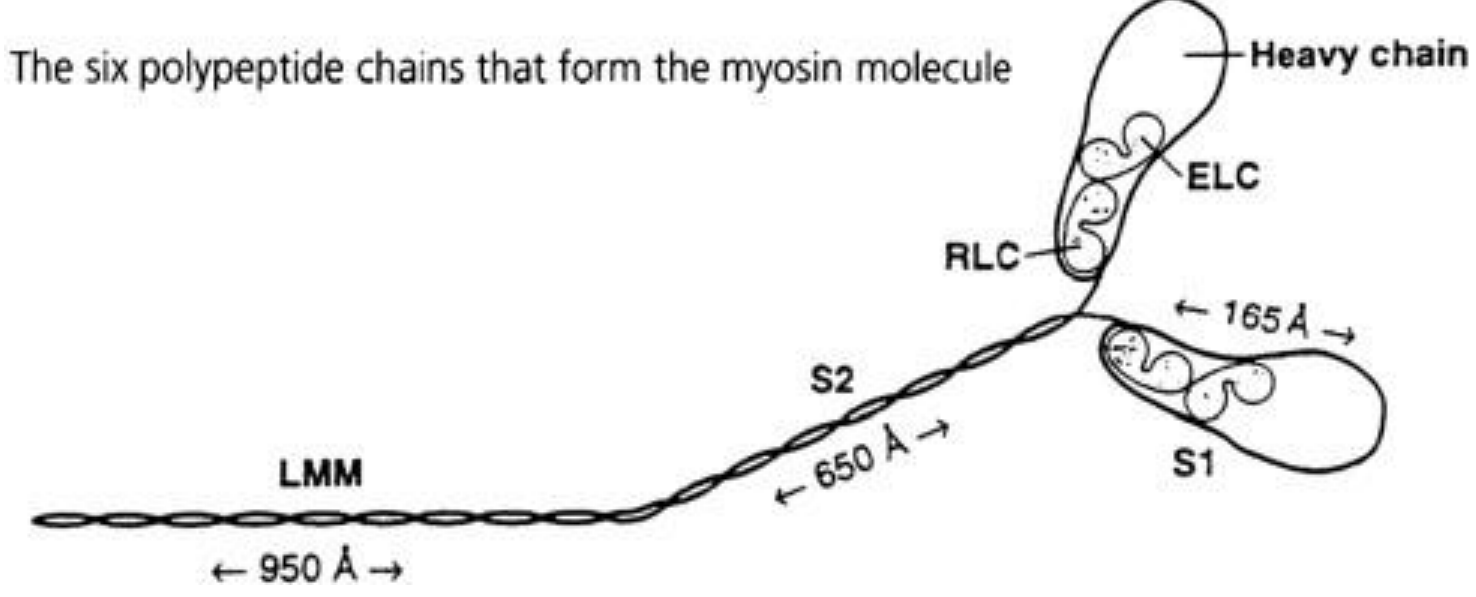

Fig. 3. Diagram of myosin molecule. From Rayment \& Holden (1994). LMM: light meromyosin, RLC: regulatory light chain; ELC: essential light chain: S1: heavy meromyosin head; S2: collar of heavy meromyosin.

\subsection{Actin filaments}

Actin filaments (or thin filaments) vary in length between species and are about $1.05 \mu \mathrm{m}$ in rabbit and $1.20 \mu \mathrm{m}$ in beef (Bendall \& Voyle, 1967). The diameter of actin filaments is 6 to 9 $\mathrm{nm}$ (Wong, Lin, Tang, Li, Janmey, \& Safinya, 2003). Actin filament components associate with nascent Z-disk structures when myofibrils are formed. Seven actin monomers are used for each half-helical turn of the actin filament. The addition of actin monomers to actin filaments requires the action of the capping proteins CapZ at the Z-disk end and tropomodulin at the $\mathrm{H}$ Zone end. Actin filaments are generated by two twisted $\alpha$ helices that associate with the regulatory proteins tropomyosin and the troponins. Tropomyosin has a molecular weight of $37 \mathrm{kDa}$ and is constructed of two $\alpha$-helical chains arranged as a coiled-coil rod. The primary function of tropomyosin is together with the troponins to regulate the interaction of myosin and actin filaments during the force generation. The troponins are a complex of three proteins: troponin-C (18 kDa), troponin-I (20 kDa) and troponin-T (30 kDa) and are present at regular intervals along the entire length of the actin filament.

\subsection{Titin, nebulin and obscurin}

Titin, nebulin and obscurin, the three giants of the sarcomere, are muscle specific proteins that play key roles in organizing sarcomeres (for reviews see Tskhovrebova \& Trinick, 2010; Kontrogianni-Konstantopoulos, Ackermann, Bowman, Yap, \& Bloch, 2009). Many of the properties of the sarcomere involves the giant protein titin (also known as connectin), which is the third most abundant protein after myosin and actin. The titin molecule spans half the sarcomere and is more than one $\mu \mathrm{m}$ long. The $\mathrm{N}$-terminus is anchored in the Z-disk and the $\mathrm{C}$-terminus in the $\mathrm{M}$-line. Titin has an elastic component in the I-band region which connects the end of the myosin filament to the Z-line. The myosin filament part of titin is fixed whereas 
the size and structure in the I-band region is varying due to different isoforms of the molecule. These isoforms range in molecular weight, and has been reported to be from around 2.4 MDa (Fritz, Wolf and Greaser, 1993) and up to around $4 \mathrm{MDa}$ in vertebrate skeletal muscle (Lindstedt \& Nishikawa, 2017). Six titin molecules are bound to each half of myosin filament. Titin is believed to define the resting sarcomere length and to keep the myosin filaments in the center of the sarcomere. Another main function of titin is to provide elasticity to the sarcomere. Titin can increase in length under applied force and decrease in length during relaxation, and conformational changes occur in the molecule during both active muscle contraction and passive extension. Titin can thus be regarded as a "molecular spring" that contributes to give striated muscle its distinct biomechanical properties during contraction, relaxation and stretch. Specific titin domains along the distance from the $\mathrm{M}$-line to the Z-disk interacts with a range of proteins, including myomesin, myosin, myosin-binding protein $\mathrm{C}$, and $\alpha$-actinin. The $Z$-disk region of titin interacts with both myofibrillar and membraneassociated proteins, suggesting that titin play an essential role in sarcomeric stability and maintenance. Nebulin, an actin-binding protein of 500 to 800 kDa (KontrogianniKonstantopoulos et al., 2009; Meyer \& Wright, 2013), is incorporated in the actin filaments and has a length of around $1.0 \mu \mathrm{m}$. In skeletal muscle nebulin constitutes 2 to $3 \%$ of the total myofibrillar proteins, corresponding to approximately 2 molecules per actin filament. The primary structure of nebulin is composed of $185 \alpha$-helical repeats and the $\mathrm{N}$-terminus extends to the ends of the actin filaments, whereas the C-terminus is partially inserted into the Z-disks. When actin filaments are formed the growth will terminate at exactly the length of nebulin, and thereby nebulin helps to organize the structure of the sarcomere. Nebulin can associate directly with titin at the Z-disk and these two proteins may act together to determine the width of the Z-disk (Witt, Burkart, Labeit, McNabb, Wu, Granzier, \& Labeit, 2006). In addition to its role in defining the sarcomeric structure nebulin might have a regulatory role in muscle contraction. Obscurin is the most recently discovered of the giant proteins in the sarcomere and it has been difficult to characterize due to its large size and insolubility (Young, Ehler, \& Gautel, 2001). Obscurin has a molecular weight of 720 to $900 \mathrm{kDa}$ and is not present within the sarcomere but surrounds them at the level of the Z-disk and M-line. Obscurin interacts with myosin and titin and also with proteins in the sarcoplasmatic reticulum membranes.

\subsection{The Z-disk}

Z-disks are the primary conduits of the force generated by contraction and constitute an anchoring point for the actin filaments as well as for titin and nebulin. The Z-disks of adjacent myofibrils are aligned which facilitates coordination of contractions between individual myofibrils. The Z-disk is a complex protein network. $\alpha$-Actinin $(97 \mathrm{kDa})$ is a major component of the Z-disk, function as an actin cross-linking protein and helps to stabilize the sarcomere structure during contraction. Other Z-disk associated proteins include muscle LIM protein (23 $\mathrm{kDa}$ ), filamin (around $300 \mathrm{kDa}$ ), telethonin (19 kDa) and MURF-3. Intermediate filaments and their associated proteins act as linkages to the cytoskeletal network and proteins such as desmin ( $52 \mathrm{kDa}$ ) are present at the periphery of the Z-disk and form the link between adjacent 
myofibrils. Thus the Z-disk is strongly involved in stabilizing the sarcomere against lateral shear forces as well as transmitting axial forces along the muscle fiber.

\subsection{The M-band}

The M-band appears as a series of parallel electron dense lines in the central region of the Aband comprising the antiparallel myosin tails. In addition, the C-terminus of titin overlaps in this region. The $\mathrm{M}$-band is a filament system cross-linking the myosin filaments and is needed for regular packing of the myosin filaments (Agarkova \& Perriard, 2005). The number of Mlines (or M-bridges) depends on the contractile characteristics of the muscle and varies with muscle fiber type. The M-band contains myomesin and M-protein, which participate in the sarcomeric cytoskeleton by binding to the central zone of myosin filaments and to the Cterminal region of titin. The $\mathrm{C}$-terminal region of myomesin undergoes antiparallel dimerization and myomesin dimers form an elastic link between myosin filaments.

\subsection{Sarcomere structure in shortening}

The shortening of a live muscle is well understood at the level of the internal structure of the sarcomeres. The length of the A-band is essentially constant during contraction, myosin and actin filaments slide past one another, and the actin filaments are being pulled further into the array of myosin filaments as the muscle shortens (Huxley, 1969). During muscle contraction the I-band becomes narrower and the Z-disks within the myofibril are drawn closer together. Upon relaxation of the muscle the filaments slide past each other in the opposite direction. During the shortening of a muscle the sarcomere may shorten by $30 \%$ or more, for example from a resting length of $2.5 \mu \mathrm{m}$ to $1.8 \mu \mathrm{m}$. At short sarcomere lengths the arrays of actin filaments meet at the M-line and with further shortening overlap. The force for shortening of the sarcomere is developed by an ATP-driven, cyclic interaction of myosin heads with actin units in the thin filaments. During a cycle a myosin head attaches to actin, undergo a conformational change which generates the force for muscle contraction, and then detaches (Geeves \& Holmes, 2005). A single myosin head can impart a 5 to $10 \mathrm{~nm}$ axial movement to an actin filament to which it is attached with a force of up to $10 \mathrm{pN}$ (Huxley, 1969; Huxley \& Simmons, 1971). At a sarcomere length of $2.2 \mu \mathrm{m}$ all the myosin heads can make contact with an actin filament, although it has been estimated that the fraction of myosin heads that attach to actin during isometric contraction is no more than 0.43 (Linari, Dobbie, Reconditi, Koubassova, Irving, Piazzesi, \& Lombardi, 1998).

The sarcomere length shortens with muscle contraction and after rigor considerable variation in sarcomere lengths within and between muscles may exist. For example, Locker (1959) reported that after rigor, the sarcomere lengths ranged from 0.7 to $3.7 \mu \mathrm{m}$ in various bovine muscles. However, sarcomere lengths below $1.1 \mu \mathrm{m}$ are not common and usually only occur with extreme shortening which is not standard (Locker, 1959, 1960, Voile; 1969). Sarcomere lengths of 2.4 to $3.7 \mu \mathrm{m}$ were observed for muscles entering rigor in the relaxed state or due to tension of individual muscles by their skeletal attachment. Such large differences in 
sarcomere length as described by Locker (1959) are, however, not normally found in beef muscle. Resting sarcomere length for bovine semitendinosus has been reported to be around $2.2 \mu \mathrm{m}$ (Herring, Cassens, Suess, Brungardt, \& Briskey, 1967). In bovine longissimus and semitendinosus (Gothard, Mullens, Boulware, \& Hansard, 1966; Stromer, Goll, \& Roth, 1967) and ovine longissimus (Wheeler \& Koohmaraie, 1994) muscles sarcomere length shortened ( 22 to $44 \%$ ) during rigor development and then lengthened (12 to $20 \%$ ) with additional postmortem storage.

Shortening of a living muscle during contraction will result in an increased diameter since the volume of the muscle is constant. It has been argued that the sarcomere diameter, as well as the transverse distances between myosin filaments also enlarges during contraction, and that the function of the $\mathrm{M}$-band is to limit excessive enlargement. The filament lattice spacing (the center-to-center distance of two neighboring myosin filaments) at different sarcomere lengths has been measured by low-angle X-ray diffraction - a technique that provides a precise measurement $( \pm 0.5 \%)$ of the distance between myosin filaments. When a relaxed muscle is stretched the lattice spacing decreases and the decrease in lattice spacing is inversely related to the square root of the length of the muscle sarcomere (Elliott, Lowy, \& Worthington, 1963). Also, in the contracting muscle the center-to-center distance between myosin filaments depends on the sarcomere length and thus Elliott, Lowy, \& Millman (1967) reported that the distance was about $8 \mathrm{~nm}$ larger in muscles with a sarcomere length of 2.1 $\mu \mathrm{m}$ than in muscles with a sarcomere length of $3.6 \mu \mathrm{m}$. It is today generally accepted the lateral distance between myosin filaments in both resting and contracting striated muscles varies with sarcomere length in such a way that the lattice volume of the muscle remains constant as the muscle changes in length. Another consideration is whether there is a change in the filament lattice when the muscle is actively contracting at a constant muscle length (isometric contraction). During isometric contraction at sarcomere lengths ranging from 1.8 to $2.7 \mu \mathrm{m}$ the transverse distances between myosin filaments was shown to remain nearly constant (Haselgrove \& Huxley, 1973), and the thickening of the contracting muscle fiber is probably achieved by displacement of sarcoplasm between the A-band and other parts of the myofibril (Millman, 1998).

\subsection{Sarcomere length in living muscle}

The synthesis of actin and myosin begins in fetus' muscles. Myofibers, consisting of actin and myosin, are the product of myoblasts which have fused to form myotubes. Initially, the nuclei are at the center line of the myotube, and there are only a few myofibrils around the nuclei. At this stage of synthesis, there is more globular actin than myosin, but soon both filaments start to develop. Then the myofibrils start to proliferate by longitudinal fission. The lateral growth of daughter myofibrils is associated to the thickness of the mother myofibril. As a consequence, the myofibrils will fill about $80 \%$ of the space, and nuclei will be pushed towards the sarcolemma. At the same time the myofibrils turn striated. It is during the initial two thirds of the prenatal period when these processes are completed. Additionally, when the muscle 
fiber is fully synthesized, the connective tissue network has developed concurrently (endomysium and perimysium). The organization of motor neurons has a role in the development of muscle fibers as tissue organizers (Jellies, 1990) and a role in differentiating the muscle fibers into the different muscle fiber types (Vrbová, Gordon, \& Jones, 1978). Postnatally, satellite cells produce new myofibrils which grow with existing muscle fibers (Seale \& Rudnicki, 2000).

The majority of muscle fiber growth takes place after birth until maturity. The diameter of the muscle fiber increases by longitudinal fission of the myofibrils, followed by the lateral growth of the daughter myofibrils (Goldspink, 1971). The fission starts at Z-disk due to the pressure caused by contraction. During contraction, the pressure will be maximal in the center of the Z-disk leading to rupture. Interestingly, the fissions require less pulling force with increasing contraction speed of the fiber. This leads to more fissions in white fiber types than in red fibers, and the sarcoplasmic reticulum is also more developed in white fibers. Transverse sarcomeric fission also takes place. The transverse splitting starts in the sarcomere at the $\mathrm{H}$ zone (Jahromi \& Charlton, 1979) in the middle of the sarcomere. The order of events may be that new myosin molecules will be added to the cut ends of myosin filaments, then actin molecules will link with the myosin S-1 fragments, and actin filaments start to develop. Finally Z-disk material starts to accumulate forming the Z-disk for the other end. The other location of transverse splitting is at the Z-disk (Long, Zhang, Wang, \& Luo, 2010), where two daughter myofibrils are formed which then start to increase in length by adding new sarcomeres in the cut ends.

The resting lengths of sarcomeres vary also with muscles and animal species. It is difficult to give one value, but the typical reported length of a sarcomere is $2.5 \mu \mathrm{m}$, which is longer than the values found in rigor muscles (around $2 \mu \mathrm{m}$ ). Wheeler, Shackelford, and Koohmaraie (2000) reported post-mortem sarcomere lengths e.g. in porcine semitendinosus $(2.45 \mu \mathrm{m})$, triceps brachii $(2.44 \mu \mathrm{m})$, longissimus $(1.78 \mu \mathrm{m})$, semimembranosus $(1.83 \mu \mathrm{m})$, and biceps femoris $(1.74 \mu \mathrm{m})$ muscles. Psoas major usually has particularly long sarcomeres; Herring, Cassens and Briskey (1965a) reported as long as $3.8 \mu \mathrm{m}$ in post-rigor excised psoas major, compared to semimembranosus having $2.4 \mu \mathrm{m}$. Such large differences suggest that there is a relationship between the sarcomere lengths of the living and the post-mortem muscles, and consequently, length differences also exist between living muscles.

Sarcomeres also grow in length with age. The increase in length does not exceed $20 \%$ greater than the length at birth. The actin filament length is partly controlled by nebulin and tropomodulin (and a large number of other proteins) (Ono, 2010) but also by the dynamics of the actin molecule binding to actin filaments, triggered by contraction (Castillo, Nowak, Littlefield, Fowler \& Littlefield, 2008). However, by far the main increase in fiber length will occur by adding new sarcomeres to the myofibrils (Goldspink, 1971; Williams and Goldspink, 1971). In living muscle, the number of sarcomeres is dynamically controlled as well: if the fibers in a muscle are mostly contracted, the quantity of sarcomeres will start to decrease, and if extended, then the quantity will increase (Goldspink, 1971; Williams \& Goldspink, 
1971). Therefore, the resting length of the sarcomeres is rather constant irrespective of body size and typical posture. However, there may be an interaction between age and muscle stretching. Williams and Goldspink (1978) found that the number of sarcomeres was a function of the long-term stretching of muscles of adult rats. However, the same observation was not found in young rats which were still growing. The authors suggested that this may be explained by the lengthening of the tendon.

Since the Huxley's cross-bridge theory of 1958, it has been agreed that each actomyosin cross-bridge is an individual player (Morgan, Claflin \& Julian, 1991) and the sarcomere lengths may differ even within the same myofibril. Morgan et al. (1991) and Stossier (2012) also claim that there is no uniform passive tension throughout the fiber, such that at rest there are sarcomeres that contract while others are relaxed. As a general conclusion, the authors suggest that when studying the extensive number of papers published in biophysical literature, it seems that meat science and technology in many cases is simplifying the phenomena taking place in muscle fibers. This may, however, be a rational approach within meat science and especially in meat technology, provided that the main features presented reflect the current knowledge of cell biology.

In recent years, there has been an increase of breast muscle dystrophies in fast-growing poultry hybrids (Kuttappan, Hargis, \& Owen, 2016). Muscles with swollen hard areas when palpating, pale color and petechiae and hemorrhages characterize the wooden breast muscle dystrophy (Sihvo, Immonen, \& Puolanne, 2014). Microscopically, there was evidence of degenerating fibers, large extracellular area, and in chronic cases fibrosis. Wooden breast syndrome is sometimes coexisting with white stripes in the muscle (white striping syndrome). These defects can be identified immediately after slaughter, i.e. they develop in living animal. It seems that the sarcomere lengths in wooden breast lesion and non-lesion sites are longer than in non-affected muscles (Soglia, Sihvo, Petracci, Cavani \& Puolanne, unpublished observations). It seems to be evident that the contractile stage is not contributing the hardness of the broiler wooden breast muscle.

\section{Postmortem muscle contraction}

\subsection{Rigor mortis}

A relaxed muscle is flexible and myosin and actin filaments can slide past one another largely unhindered by interactions between myosin and actin. As individual muscle fibers become exhausted of supplies of energy they lose extensibility and enter rigor. The term rigor mortis refers to the muscle stiffness that occurs after all muscle fibers enter rigor. Bate-Smith (1939) reported a 10-fold change in elasticity of muscle undergoing rigor mortis. The main biochemical events in muscle related to the onset of rigor mortis can be summarized as: 
1) Depletion of myoglobin-bound oxygen after death of the animal and cessation of mitochondrial respiration.

2) Shift from aerobic to anaerobic metabolism. The rate and extend of glycolysis in combination with external cooling will lead the muscle through different combinations of $\mathrm{pH}$ and temperature.

3) Disappearance of creatine phosphate soon time after death.

4) Disappearance of ATP, which begins after the creatine phosphate has declined.

5) Increase in free $\mathrm{Ca}^{2+}$ in sarcoplasm.

6) Formation of cross-links between myosin S-1 heads and actin resulting in actomyosin. The muscle becomes stiff and looses elasticity.

Pioneering studies of Bate-Smith and Bendall (1947) established the main features of some of the biochemical events leading to rigor onset in striated muscle. The onset and development of rigor was correlated with breakdown of ATP (Bate-Smith \& Bendall, 1947), and using rabbit psoas muscles the same authors (1949) showed that the time-course of rigor mortis was greatly influenced by the at-death glycogen reserve. Bendall (1951) found that the creatine phosphate decreased rapidly postmortem, that the ATP fall was accelerated when the creatine phosphate level had been reduced to less than $30 \%$ of its initial value and that no changes in the length or extensibility occurred in the muscles until the ATP content had fallen below $80 \%$ of its resting level. At further decreasing levels of ATP, however, the extensibility of the muscle will decrease. During development of rigor mortis there is a great variation between animals in the interval between death and the first signs of stiffening of the muscles. The disappearance of ATP does not occur simultaneously across and within muscles. Using single muscle fibers Jeacocke (1984) showed that each fiber had its own time course to enter rigor and suggested that the differences depended on the initial fiber glycogen level.

The sarcoplasmic free calcium ion concentration is only maintained at a low level by the $\mathrm{Ca}^{2+}$ pumps of the sarcoplasmic reticulum and mitochondria - a process that is driven by hydrolysis of ATP. In a relaxed muscle the free calcium is around $0.1 \mu \mathrm{M}$ and it can rise to more than 5 $\mu \mathrm{M}$ during contraction. In the postmortem muscle there is a gradual increase in free calcium due to leakage into the sarcoplasm accompanied by loss of the calcium-accumulating ability of the sarcoplasmic reticulum and the mitochondria along with the disappearance of ATP. Various results have been reported on the post-rigor free calcium concentration in meat. The free calcium after the onset of rigor was reported to increase to more than $100 \mu \mathrm{M}$ in mouse muscle fibers (Jeacocke, 1993) and to $110 \mu \mathrm{M}$ when the $\mathrm{pH}$ had decreased to 5.5 in lamb longissimus muscle (Hopkins \& Thompson, 2001). Geesink, Tayler, Bekhit \& Bickerstaffe, 2001 reported that in lamb longissimus muscle the concentration increased from $106 \mu \mathrm{M}$ at day 1 to $189 \mu \mathrm{M}$ at day 7 post-mortem and Pomponio \& Ertbjerg, 2012 found it to be around 440 $\mu \mathrm{M}$ in pork longissimus muscle. In various muscles from rabbit, pig, beef and chicken a free calcium concentration of approximately $220 \mu \mathrm{M}$ was reported (Ji \& Takahashi, 2006). 
Depending on the temperature conditions, the calcium release from the sarcoplasmic reticulum into the sarcoplasm will accompany the entry of a fiber into rigor, and thereby participate in a relatively normal calcium-induced contraction prior to rigor onset. When a muscle passes into rigor at a constant sarcomere length there is a radial movement of myosin S-1 heads out from the myosin filaments when they attach to actin filaments (Huxley \& Brown, 1967), and as the ATP concentration drops from its normal physiological level of around $5 \mathrm{mM}$ to well below $0.1 \mathrm{mM}$ a substantial interaction between myosin and actin occurs. This will result in persistent actomyosin complexes which prevent sliding of myosin and actin filaments. The change in extensibility and formation of cross-links is accompanied by a shortening of the muscle. If the muscle goes into rigor at around 10 to $15^{\circ} \mathrm{C}$, this shortening is only small. Thus Bendall (1951) reported a $10 \%$ decrease in muscle length of the initial length under a load of $50 \mathrm{~g} / \mathrm{cm}^{2}$ at a rigor temperature of $17^{\circ} \mathrm{C}$. The rate of rigor development is different depending on species. Rigor mortis progresses faster in lamb than in beef muscles (Marsh \& Thompson, 1958), more rapidly in pig and very fast in poultry.

\subsection{Thaw rigor}

If muscles are frozen pre-rigor they will develop a strong contraction upon thawing. This phenomenon is known as thaw rigor or thaw contracture. After pre-rigor freezing in liquid nitrogen of a cat hind limb muscle, it was described as quite short and thick and having contracted appearance (Lundsgaard, 1950), and thawing of frog sartorius muscle was accompanied by a decrease in length of $70 \%$ (Perry, 1950). As for normal muscle contraction, the force is developed by splitting of ATP. Thus Borbiro \& Szent-Györgyi (1949) demonstrated that the tension developed during contraction upon thawing of rabbit psoas muscle decreased proportionately to the level of ATP in the muscle. As for other types of muscle contractions, the trigger for thaw rigor is the release of the $\mathrm{Ca}^{2+}$ ion (Kushmerick \& Davies, 1968). During freezing ice crystals grows and penetrate the sarcoplasmic reticulum. Subsequent thawing of the crystals enables a rapid release of $\mathrm{Ca}^{2+}$ into the sarcoplasm which is faster than the removal of these ions by calcium pumps, resulting in a build-up of $\mathrm{Ca}^{2+}$ to the level at which contraction occurs. The thawing rate is of importance for the rate of development of rigor mortis and the contraction. Thus, for pre-rigor frozen lamb muscles, shortening values increased with increasing thawing temperature (Cook \& Langsworth, 1966). Lowering the temperature of pre-rigor meat slightly below zero increases the rate of rigor mortis development. A maximum rate is observed around $-3^{\circ} \mathrm{C}$, and at lower temperatures the rate of rigor declines and is arrested below about $-20^{\circ} \mathrm{C}$ (Behnke Fennema, \& Cassens, 1973; Marsh, 1958). Ice will be formed in muscle at a temperature between -1 and $-2{ }^{\circ} \mathrm{C}$, and although rigor proceeds the presence of ice will prevent contraction. Therefore slow thawing can prevent the contraction of pre-rigor frozen lamb (Davey \& Gilbert, 1973). Thaw rigor can produce increased drip loss (Marsh \& Thompson, 1956 and 1958) and very appreciable 
toughening of meat after cooking (Marsh \& Leet, 1966; Marsh, Woodhams \& Leet, 1968; Davey \& Gilbert, 1973). Thaw rigor can be eliminated by freezing meat only after it has gone into full rigor.

\subsection{Cold shortening}

Exposure of pre-rigor muscle to temperatures near freezing point causes muscle contraction known as cold shortening (for review see Locker, 1985). Cold shortening is a factor to consider in meat processing wherever freshly slaughtered meat is exposed to rapid chilling. In a classic study by Locker \& Hagyard (1963) shortening of excised beef sternomandibularis muscle was observed to depend on the temperature in passing into rigor mortis (Fig. 4).

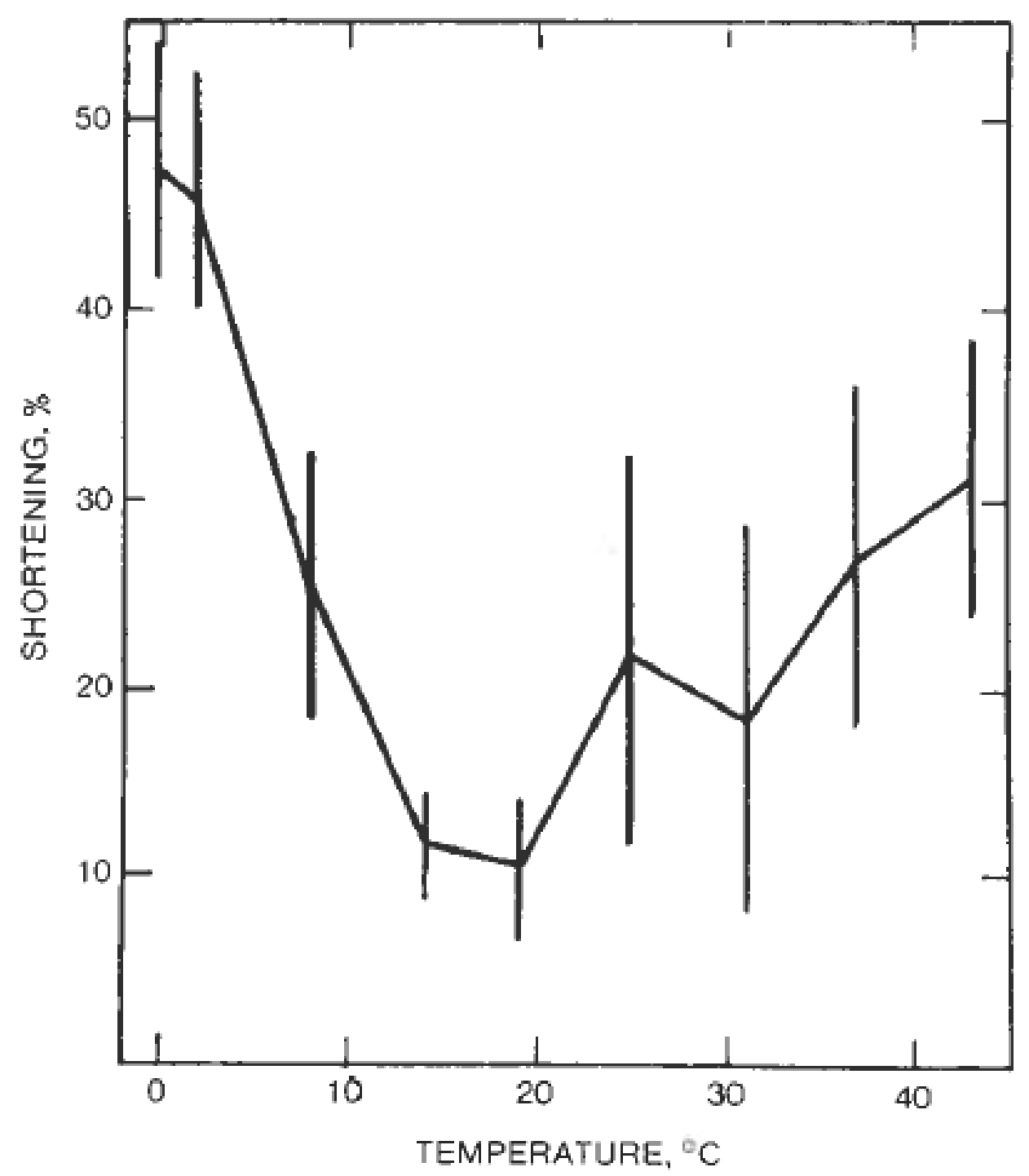

Fig. 4. Shortening of excised bovine sternomandibuaris muscle in relation to holding temperature during rigor development. The mean final shortenings from pre-rigor to post- 
rigor as percentage of initial length are shown together with the standard deviation. From Locker and Hagyard (1963).

A minimum of shortening was observed at 14 to $19^{\circ} \mathrm{C}$ (around $10 \%$ shortening) and shortening was more at $0^{\circ} \mathrm{C}\left(48 \%\right.$ shortening) than at $43^{\circ} \mathrm{C}$ (around $30 \%$ shortening). Similar results were obtained for longissimus muscle. The lower the temperature below $14^{\circ} \mathrm{C}$, the greater was the degree of cold shortening. These observations led to a more detailed exploration of the effects of rigor temperature on the contraction state of the muscle and the effect on meat tenderness (see section 4.1 for description of the relationship to tenderness). Only pre-rigor muscles can cold shorten as the ATP levels are critical to the contraction process. The rate as well as the extent of cold shortening is dependent on the degree of rigor onset at the time of cooling (Marsh \& Leet, 1966). Cold shortening is most rapid at the first 1-2 hours at low temperature. Thereafter, shortening becomes progressively slower but continues until rigor. The shortening at cold temperatures (Locker \& Hagyard, 1963) could be reversed at the early post-mortem stage by placing the contracted muscles at a temperature of $22{ }^{\circ} \mathrm{C}$. After completion of rigor the process of cold shortening has been regarded as irreversible, although some lengthening of the sarcomeres during ageing following cold shortening has been reported (Feldhusen \& Kühne, 1992). Cold shortening is in many respects similar to normal muscle contraction, but it progresses extremely slowly. The tension of muscle that develops due to cold shortening can be substantial, but is lower than that generated during thaw rigor. Cold shortening is widely observed among species; muscles from beef, lamb, pig, chicken and turkey actively cold shorten. Porcine muscles demonstrate a lesser capacity, whereas rabbit is an exception being much less sensitive to the phenomenon (Galloway \& Goll, 1967; Bendall, 1975). The onset of cold shortening in porcine muscles occurs at lower temperatures compared to that of bovine muscles (Fischer, Honikel, \& Hamm, 1980). Excised red muscles generally cold shorten more extensively than white muscles, however, in pig the longissimus muscle cold shortens more forcefully than other muscles (Bendall, 1975). One reason that the longissimus muscle also in practice is sensitive to cold shortening is likely the attached structure whereby the fibers are firmly anchored to the skeletal framework at one end only. The propensity of red muscles to cold shorten has been suggested to be related to the high mitochondrial content (Buege \& Marsh, 1975). The mechanism of cold shortening is believed to be due to diminished functioning at low temperatures of the calcium pumps in the sarcoplasmic reticulum, whereas $\mathrm{Ca}^{2+}$ in the mitochondria may serve as a source for increased concentrations in the sarcoplasm (Cornforth, Pearson, \& Merkel, 1980).

For cold shortening the distance from the muscle surface may be of importance, as it influences the time-temperature relationship and therefore also the rates of ATP depletion and the $\mathrm{pH}$ fall. Puolanne and Ruusunen (1998) found that, in fixed muscle stripes in a linear temperature gradient of $4-14{ }^{\circ} \mathrm{C}$ along the fiber axis, there is a shortening at $4{ }^{\circ} \mathrm{C}(\mathrm{Fig} .5 \mathrm{~A})$ and an elongation and fractures at $14^{\circ} \mathrm{C}$ (Fig. 5B). They hypothesized that therefore the 
contraction is different in carcasses as well, due the temperature-time profile within the muscle and fiber orientation in relation to the temperature flow.

A, $4{ }^{\circ} \mathrm{C}$ end

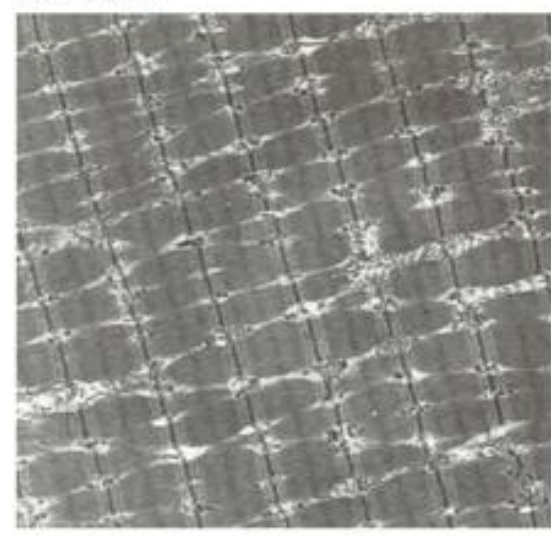

$2 \mu \mathrm{m}$
$\mathrm{B}, 14^{\circ} \mathrm{C}$ end

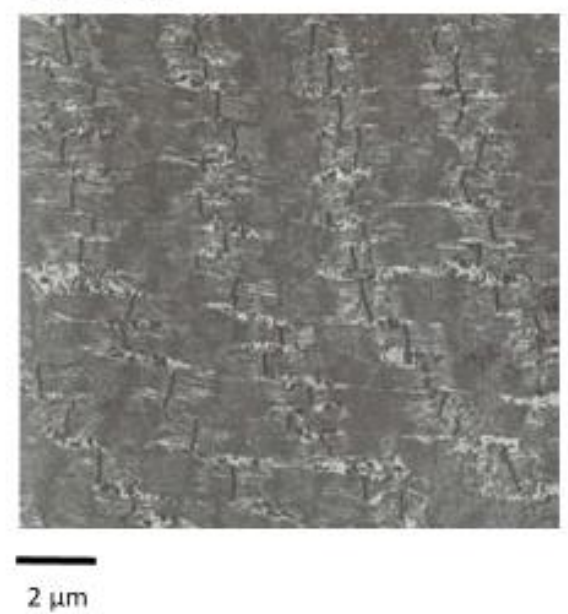

Fig. 5. Transmission electron micrographs of pre-rigor (30 min. postmortem) bovine $M$. longissimus thoracis showing sarcomere lengths and structure of meat strips $(3 * 5 * 100 \mathrm{~mm}$; the two larger dimensions lying on the gradient plate), cut along the fiber axis, fixed into a $100 \mathrm{~mm}$ linear temperature gradient plate of $4-14{ }^{\circ} \mathrm{C}$. A: the $14{ }^{\circ} \mathrm{C}$ end, $\mathrm{B}$ : the $4^{\circ} \mathrm{C}$ end. Note the short sarcomeres in $4{ }^{\circ} \mathrm{C}$ and longer, broken sarcomeres in the $14{ }^{\circ} \mathrm{C}$ end (Puolanne and Ruusunen, 1998).

\subsection{Heat shortening}

The shortening that results from keeping muscle at high temperature pre-rigor is called heat shortening or rigor shortening. Early studies reported shortening of rabbit (Bendall, 1951) and beef (Marsh, 1954) muscles passing into rigor at elevated temperature. The effect of temperature on shortening is less at high temperatures $\left(20\right.$ to $\left.40^{\circ} \mathrm{C}\right)$ than observed at low temperatures in the cold shortening range $\left(0\right.$ to $\left.15^{\circ} \mathrm{C}\right)$. In rigor contraction at temperatures higher than $20^{\circ} \mathrm{C}$, the fibers that have already entered the state of rigor might restrain the contraction of other fibers that are about to go into rigor. This can explain why the extent of rigor contraction of a muscle as a whole is smaller than that of cold contraction, where the contraction is completed before the fibers enter rigor. 


\section{Biophysical aspects}

\subsection{Tenderness}

It is well documented that muscle entering rigor in the contracted state can result in tough meat in beef (Locker, 1960; Herring, Cassens \& Briskey, 1965 a; Marsh \& Leet, 1966), in lamb (Marsh, Woodhams \& Leet, 1968; McCrae, Seccombe, Marsh, \& Carse, 1971) and in pork (Marsh, Briskey, Cassens, \& Kauffman, 1972; Dransfield \& Lockyer, 1985; Moller, Kirkegaard, \& Vestergaard, 1987). Toughening due to short sarcomere lengths has been most widely studied in relation to cold shortening, but is also observed after muscle shortening due to thaw rigor and rigor shortening. Thus, during rigor development of ovine longissimus muscle Wheeler \& Koohmaraie (1994) demonstrated that shear force values increased as the sarcomere length decreased from $2.24 \mu \mathrm{m}$ at-death to $1.69 \mu \mathrm{m}$ at 24 hours post-mortem. The cause of the toughening was due to the rigor shortening as shear force values did not increase when muscle was prevented from shortening (Koohmaraie, Doumit, \& Wheeler, 1996).

Toughening of meat due to short sarcomeres is observed after cooking, and not in raw meat (Rhodes \& Dransfield, 1974; Davey \& Gilbert, 1975). The relationship between sarcomere length and cooked meat tenderness of pre-rigor excised beef sternomandibularis muscle shows two distinct phases (Fig. 6). Toughness increases with the degree of muscle shortening up to rigor, resulting in maximum toughness at about 35 to $40 \%$ shortening (Marsh \& Leet, 1966; Davey, Kuttel, \& Gilbert, 1967; Marsh \& Carse, 1974), corresponding to a sarcomere length of 1.3 to $1.4 \mu \mathrm{m}$. The increase in shear-force values can be as large as four to five-fold when muscle shortening proceed from $20 \%$ to $40 \%$. With further shortening the toughness declines towards the relative low initial value as the change in length approaches $60 \%$ shortening. Other studies have also associated muscle shortening greater than $40 \%$ with increased meat tenderness (Behnke et al., 1973; Davey \& Gilbert, 1975).

The influence of sarcomere shortening on meat toughness is thus well documented and may be explained by several mechanisms. At a sarcomere length of $1.6 \mu \mathrm{m}$, the tips of the myosin filaments reach the Z-disks. At around $1.3 \mu \mathrm{m}$, which is the shortening range associated with maximum toughness, the myosin filament penetrate the Z-disk (Marsh \& Carse, 1974; Marsh, Leet \& Dickson, 1974). The resulting overlap of myosin filaments from one sarcomere with actin filaments to the next may, after formation of rigor cross-bridges, form a continuously linked actomyosin extending over a larger segment of the myofibril. Subsequent heat treatment results in coagulation of the protein network and tough meat. Meat at maximum toughness is uniformly shortened and shows no major signs of structural damage, but with further shortening increasing super-contraction and node formation take place. The highly contracted zones are three to twenty sarcomeres in length and extend irregularly across the width of the fiber. At very short sarcomere lengths myofibrils within a sarcomere can be ruptured by the shortening of neighboring sarcomeres (Voyle, 1969). At 50\% shortening, 
localized shortening of as much as $80 \%$ can be observed in some sarcomeres. When muscle shortens to $55 \%$ of its initial excised length, a number of super-contracted sarcomeres fracture at weak zones immediately adjacent to the Z-line (Marsh et al., 1974). These fractures could very well account for the reduced toughness at muscle shortening greater than $40 \%$.

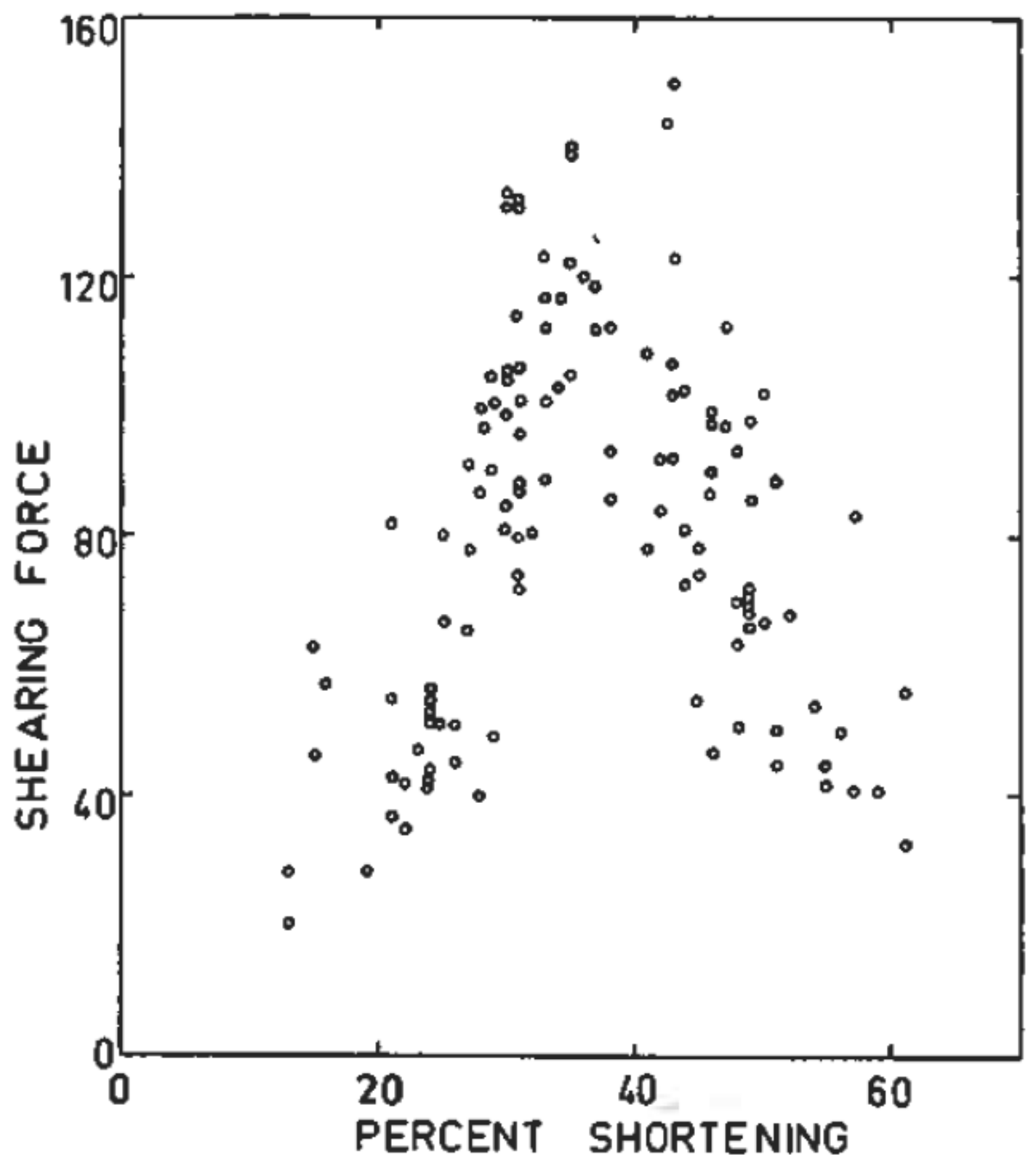

Fig. 6. Shear force values $(\mathrm{N})$ of cooked post-rigor bovine sternomandibuaris muscle at different levels of percent shortening expressed as a proportion of initial excised length prerigor. Shortening was induced by thaw rigor, cold shortening or rigor shortening. From Marsh and Leet (1966). 


\subsection{Water-holding capacity in raw meat}

The basic mechanism of water-holding in meat is very complex and only partly understood. The main theories to explain water-holding include the effect of electrostatic repulsion between the myosin and actin filaments (Hamm, 1972), osmotic and capillary forces (Offer \& Knight, 1988), the surface area of proteins interacting with sarcoplasm and the structure of water (Puolanne \& Halonen, 2010). When the tenderness and sarcomeres are discussed, the focus is on the sarcomere length, or more precisely, on the contractile status of the sarcomere. In the water-holding the focus is on the (average) volume of the contractile unit, (i.e. the unit cell volume which is the sarcomere length times the cross-sectional area of the unit cell). Especially Offer \& Knight (1988) discuss how losses of water can result from a change in volume of the myofibrils with special emphasis on the filament lattice distances. The unit cell cross-sectional area is illustrated in Fig. 2: when four adjacent myosin filaments are centerto-center linked with lines, and the same area is obtained when six actin filaments are connected also center-to-center by lines (Offer and Knight, 1988).

The mechanisms of water-holding are commonly attributed to the net charges of the parallel actin and myosin filaments causing an electrostatic push (Hamm, 1972, Offer \& Knight, 1988). It is assumed that the swelling forces are increased when the net charges in the filaments are similar. This theory is still debated as it is difficult to say whether the lattice spacing is a result of the different charges or due to other structural mechanisms and forces. For example, during rigor mortis, actomyosin bonds cause a transverse and longitudinal pull within the sarcomere which results in elastic pressure, (Offer and Knight, 1988). On the other hand, Offer and Knight (1988) also claim that in some cases the actomyosin bond may be a supporting factor to prohibit further transverse shrinking of the myofibrils. The pull depends on $\mathrm{pH}$ and temperature (denaturation of S-1 fragments, Offer and Knight, 1988). The hypothesis is supported by Vada-Kovács (1994) who showed that water-holding capacity is lower at long sarcomere lengths when incubated pre-rigor at $36^{\circ} \mathrm{C}$. Liu, Arner, Puolanne, \& Ertbjerg (2016) hypothesized that, when the water-soluble proteins have denatured during rigor development, depending on $\mathrm{pH}$ and temperature, a supporting system between the filaments may be formed. It should be mentioned, however, that the filaments in the sarcomere are not fully linear. With the exception of very long sarcomeres, the myofibrillar system is barrellike due to bending of the actin filaments close to the-disk (Goldspink, 1971). As a result, the lattice spacing is larger at the M-line than at the Z-disk.

One aspect that has been neglected so far is the role of the S-2 and S-1 fragments of myosin filaments. Their number is 250-300 double chains per myosin filament. The S-1 + S-2 (the twochain heavy meromyosin projections are here considered as one unit) fragments are arranged as a 3-stranded 9/1 organization (Squire, 2009) as shown in Fig. 7, where the filament surface is opened and depicted from round to plateau. As it can be seen from Fig. 7, on the right hand side, the S-1 + S-2 fragments at the same cross-sectional location of the three parallel strands 
have an angle of 120 degrees in relation each other. Using a myosin filament diameter of 16 $\mathrm{nm}$, the distance between two neighboring S-1 + S-2 fragments at the same cross-sectional location on the myosin shaft surface level is $16.7 \mathrm{~nm}$, but because they point directly outwards of the round surface in relation to cross-sectional projection of the filament shaft, the tips of the sidechains (S-1 fragments) of the same strand are about 30-40 $\mathrm{nm}$ away from each other, depending on how far the S-1 fragment is from the surface of the myosin shaft in each particular case. . The distance between two neighboring strands at the myosin shaft surface level is $14.3 \mathrm{~nm}$, and the distance to the closest one at the next strand is about $17 \mathrm{~nm}$. However, as the dimensions of the two S-1 fragments are $7 * 11 * 4 \mathrm{~nm}$ each (Puolanne \& Halonen, 2010), it means that the surface distances between each pair of S-1 + S-2 fragments to the closest ones are rather small. This is, measured as numbers of water layers of ice-like low density (LD) water which may be the most abundant compartment of myowater (Puolanne \& Halonen, 2010). Using this method it is calculated that the volume occupied by S1 units within the sarcomere is around $6-8 \%$ of the total volume at a sarcomere length of 2.0 $\mu \mathrm{m}$ and a lattice distance (d) of $38 \mathrm{~nm}$. The S-1units thus constitute a substantial part of the overall structure, and their role in water-holding should therefore be considered.

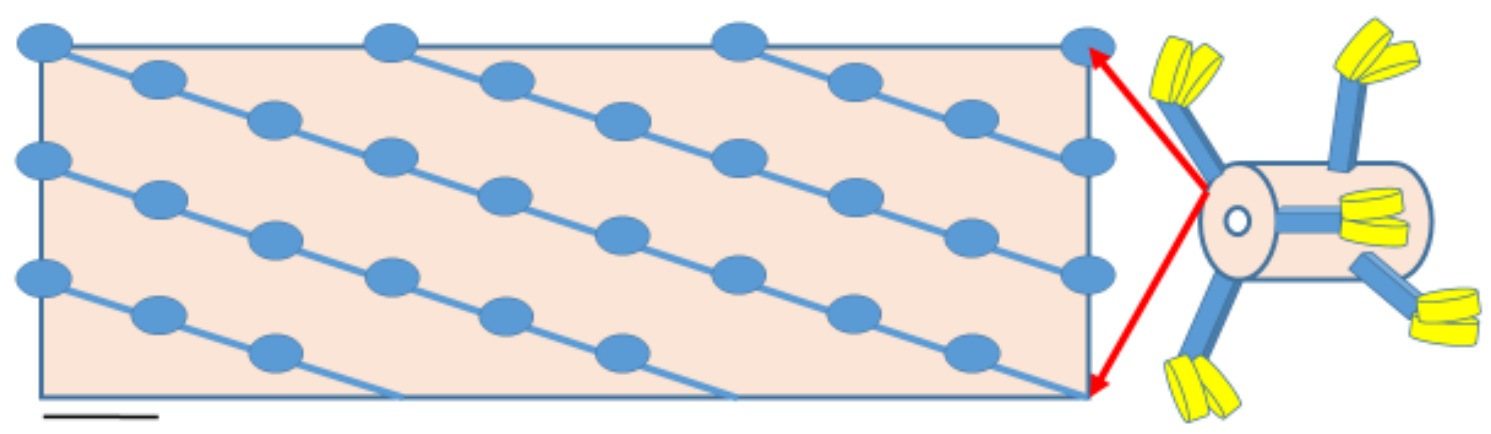

$14.3 \mathrm{~nm}$

$43 \mathrm{~nm}$

Fig. 7. Diagram of the positions of the $S-1$ and $S-2$ units in myosin filament in a mammalian striated muscle. The figure illustrates the positions of S-1 (yellow) and S-2 (blue) units of the three-dimensional structure (right side) and the corresponding "opened" two-dimensional pattern of the position of S-2 units on the filament surface (left side). There are three parallel strands and the units are repeated 9 times for each rotation of a strand around the filament. 
As the S-1 + S-2 fragments comprise about two thirds of water accessible surface area (WASA) of actomyosin it may be considered that they have a relevant effect on water holding (Puolanne and Halonen, 2010). Their surface area will not change much with sarcomere length. In addition, the cross-bridges may become more extended with shorter sarcomeres. Furthermore, the projection angle of free (not bound to actin) S-1 + S-2 fragments is not known, so it means that they may lay on the surface of the myosin shaft, depending on the net charges within the myosin filament shafts and S-1 fragments. Therefore, the effect of sarcomere length on water-holding capacity is not a simple matter.

It is well-known, however, that a contraction post mortem has an effect on water-holding. One possibility is that the reduction in water-holding at shorter sarcomere lengths is due the stronger pull created by the larger number of cross-bridges. Alternatively, it could be the sarcomere shortening itself causing longer distances between longitudinal filaments and therefore reduced electrostatic repulsion. When muscle goes into rigor in the contracted state the water-holding capacity of the meat is reduced, compared to longer sarcomeres. Marsh \& Leet (1966) found that strips of thaw rigor beef sternomandibularis muscle released a small quantity of fluid below $30 \%$ shortening, but above $40 \%$ shortening the rate of drip release increased rapidly. Later, Bouton, Harris \& Shorthose (1972) reported that the waterholding capacity of lamb longissimus muscle is reduced by cold shortening. Also various cold shortened and heat shortened beef and pork muscles showed increased drip after being stored for a number of days (Honikel \& Hamm, 1978; Honikel, Kim, Hamm, \& Roncales, 1986; Hughes, Oiseth, Purslow \& Warner, 2014) as illustrated in Fig. 8, where a hyperbolic nature of the relationship is indicated, suggesting that also a lateral shrinkage is involved.

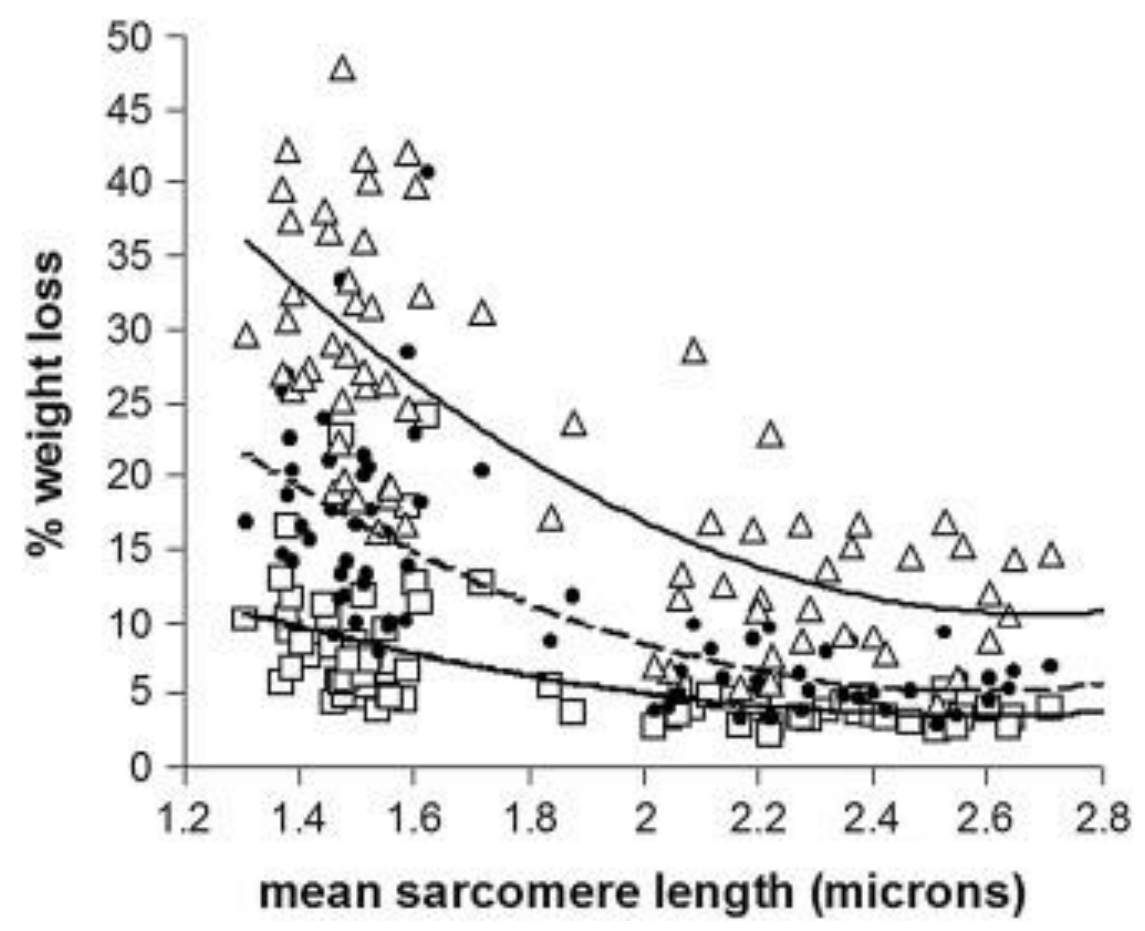

Fig. 8. Percent weight loss vs. sarcomere length at $48 \mathrm{~h}$ (open squares), $\mathbf{7 2} \mathrm{h}$ (filled circles) and $144 \mathrm{~h}$ (open triangles) post-mortem in porcine longissimus muscle. Samples 
(approximately $2 \times 2 \times 4 \mathrm{~cm}$ ) were suspended in netting in bags and the cumulative drip loss was calculated as the percentage weight loss. From Hughes et al. (2014).

However, van Laack and Solomon (1994) found a linear negative relationship between sarcomere length and amount of drip also at very short sarcomere lengths. The drip loss of both beef and pork muscles was lowest when the muscles entered rigor at about $12{ }^{\circ} \mathrm{C}$, which corresponds well with the minimum shortening of the sarcomeres. For an understanding of the relationship between the sarcomere structure and water-holding, the distances between myosin and actin filaments during contraction and rigor should also be considered. As the muscle enters rigor, there is a change in the structure of the sarcomere resulting from an overall shrinkage of myofibrils and from shortening of the sarcomere. As observed for the live muscle during stretch and contraction, the post-rigor sarcomere length is related to the fiber diameter. Herring, Cassens, \& Briskey (1965b) investigated the influence of carcass position on beef muscle contraction during rigor, and noted a negative correlation between sarcomere length and fiber diameter. The myofibrils shrink as rigor sets in due to the $\mathrm{pH}$ fall, the attachment of myosin heads to actin and the denaturation of myosin. In beef rectus abdominus muscle the spacing between myosin filaments decreased by $4.4 \%$ during rigor development (Offer \& Knight, 1988). This change may at least partly account for the amount of drip formed as the cross-sectional area of myofibrils depends on the square of the spacing. The filament lattice spacing in pork loin 24 hours post-mortem was by Irving, Swatland \& Millman (1989) found to range from 39 to $46 \mathrm{~nm}$ and they reported that the myofilaments of PSE pork were more closely packed than those of DFD pork. A rapid decrease in filament spacing was observed from 1 hour to 3 hours post-mortem, and decreasing $\mathrm{pH}$ was a key factor in lattice shrinkage post-mortem (Diesbourg, Swatland, \& Millman, 1988). Later Schäfer, Knight, Wess, \& Purslow (2000) investigated the influence of sarcomere length on the myofilament spacing in pork loin from pre-rigor to post-rigor. Some samples were cold shortened and other stretched resulting in sarcomere lengths ranging from 1.47 to $3.16 \mu \mathrm{m}$. The filament spacing decreased due to rigor at short but not at long sarcomere length (Fig. 9).

At very long sarcomere lengths there is no overlap of myosin and actin filaments. We suggest that this may explain why there is no difference in filament spacing before and after rigor by the following two $\mathrm{pH}$ related mechanisms. $i$ ) Rigor/post-rigor the $\mathrm{pH}$ is close to the isoelectric point of the major myofibrillar proteins (5.0-5.2, depending on minerals bound (Hamm, 1972)), resulting in a decreased negative charge density along the surface of myosin and actin filaments. An overall lower charge will reduce the repulsive forces between filaments. A rigorinduced shrinkage of the filament lattice occurs in the region of the A-band if the myosin and actin filaments overlap. With increasing sarcomere length the degree of myosin and actin filament overlap becomes less and hence also the repulsion between the filaments. At a sarcomere length of $3.6 \mu \mathrm{m}$ there is no overlap of myosin and actin filaments and therefore no effect of rigor on lattice spacing is seen at these very long lengths. ii) Denaturation of part 
of myosin after formation of actomyosin may induce shrinkage (Offer \& Knight, 1988) which brings the filaments closer together in regions where the myosin heads attach to actin. Also this mechanism will only affect the region where the myosin and actin filaments overlap and therefore the effect will decrease with increasing sarcomere length. In addition to the above, according to the hypothesis of Puolanne and Halonen (2010) on water accessible surface area, it can be noted that the S-1 + S-2 fragments are not bound to actin at very long sarcomere lengths which suggests that they may have a maximal possibility to interact with cellular water and thus influence the water-holding.

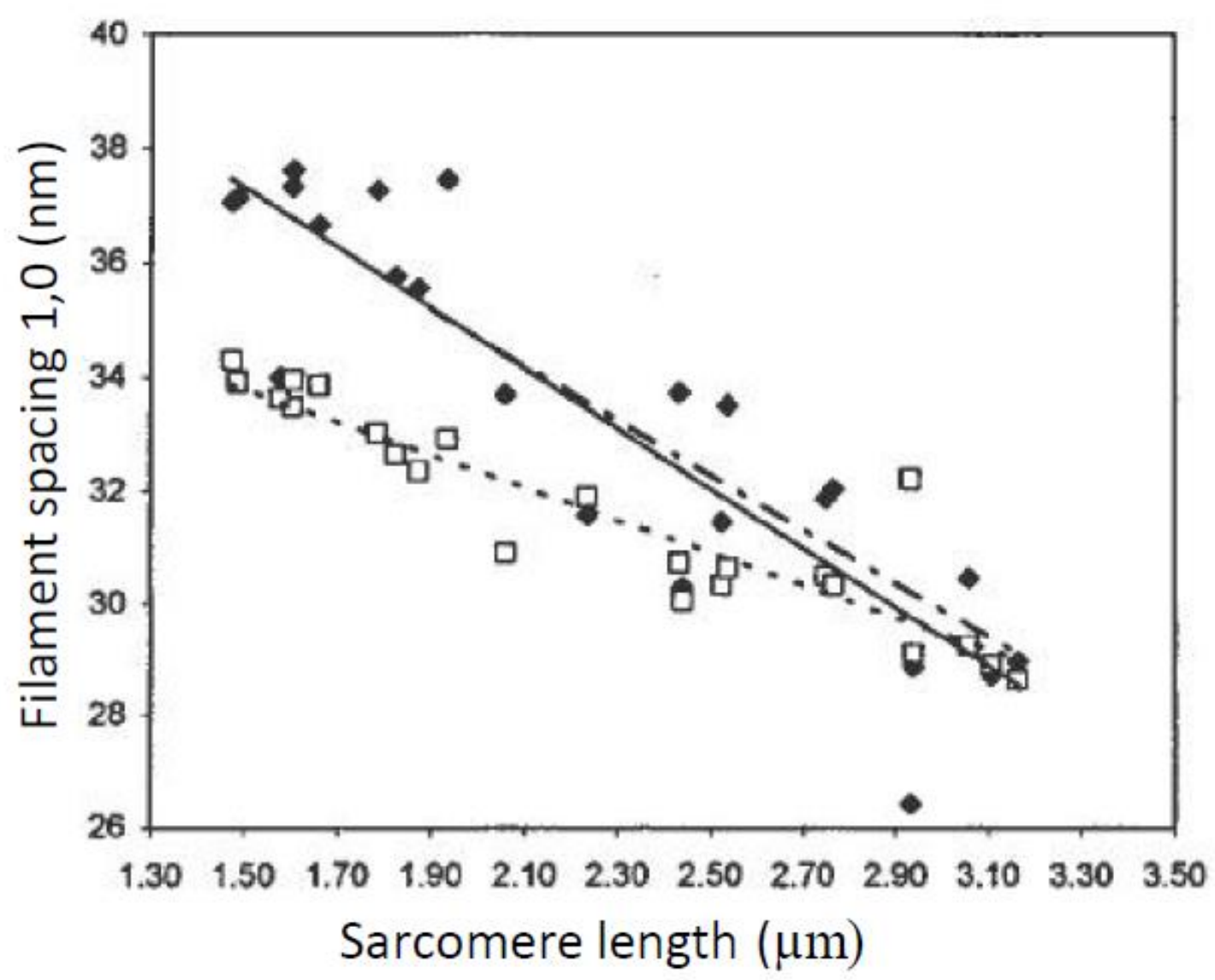

Fig. 9. Myofilament lattice spacing from pre- to post-rigor in relation to sarcomere length. Initial spacing $1 \mathrm{~h}$ post-mortem $(\diamond)$ and final spacing $24 \mathrm{~h}$ post-mortem $(\square)$ was determined from x-ray diffraction patterns of porcine longissimus muscle stretched to different sarcomere lengths. The upper broken line is the constant volume line. The unbroken and dotted lines are the linear regression lines of initial and final spacing, respectively. From Schäfer, Wess and Purslow (2000).

The release of water from meat after pre-rigor muscle shortening may be explained based on structural changes within the sarcomere. These changes involves the degree of overlap of myosin and actin filaments and the number of cross-links between them during rigor 
development, the lattice spacing between the filaments and the $\mathrm{pH}$-induced shrinkage of the protein structures as rigor sets in (Fig. 10). When the volume of the sarcomere shrinks the sarcoplasm will be expelled and with time accumulate in gaps between the endomysial network and myofibrils and migrate further to the area of the perimysium. Eventually some fluid will appear as drip on the surface of the meat. It follows that the formation of drip loss is an ongoing process that involves transfer of water from myofibrils to the extracellular space and that different water populations must exist within and outside the myofibrils (Hughes et al., 2014). The existence of three distinct water populations in pork longissimus was demonstrated by NMR measurements, and a negative relationship between sarcomere length and drip loss was observed by Bertram et al., 2002, Fig. 10).

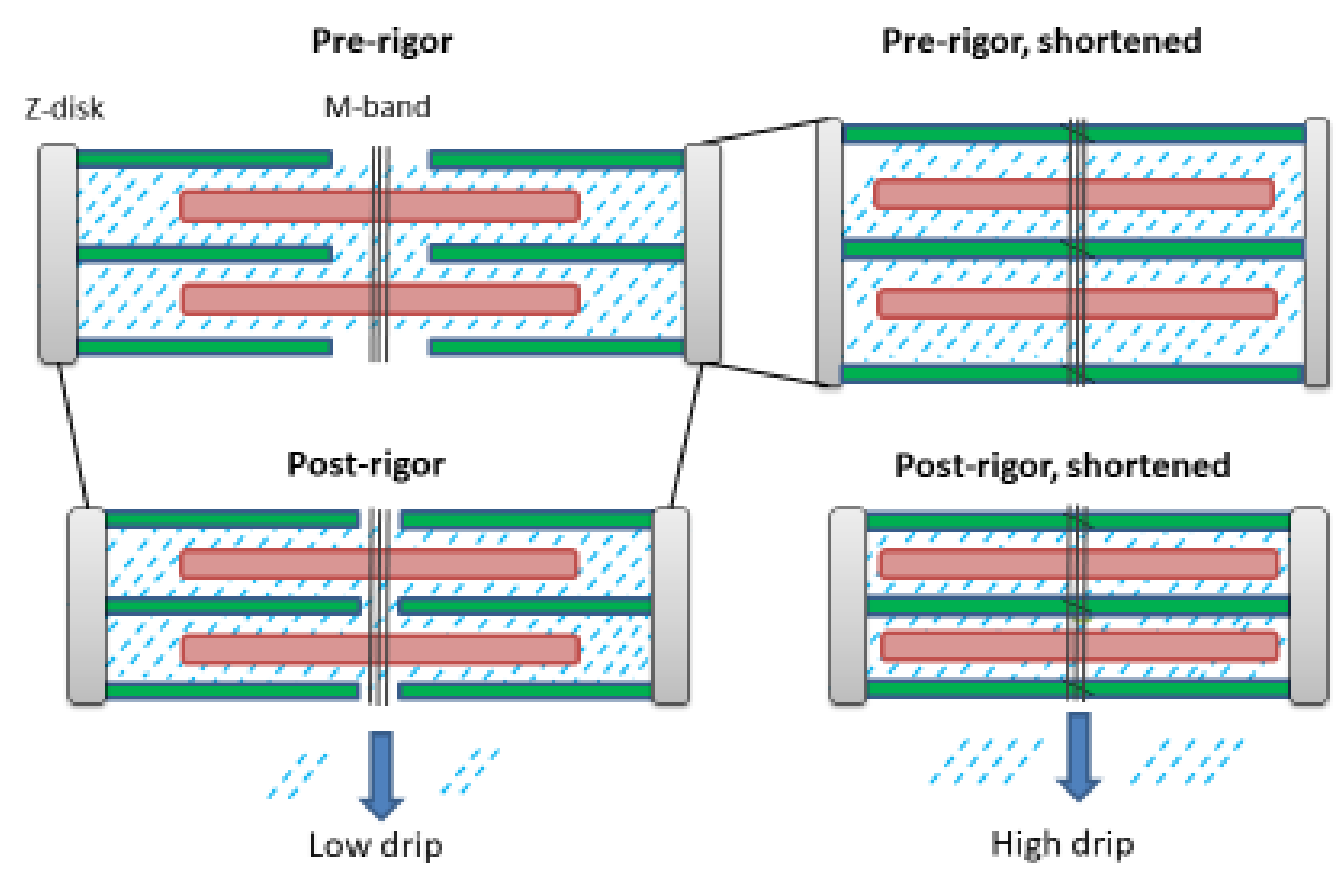

Fig. 10. Diagram showing changes in the length and width of the sarcomere during onset of rigor in relaxed and stretched sarcomeres, and the hypothesized changes in water loss (as drip). Left side illustrates relaxed and right side contracted sarcomeres. Pre-rigor shortening results in increased diameter due to the constant volume of the sarcomere during contraction. During rigor there is an additional, smaller contraction, and a $\mathrm{pH}$-induced lateral shrinkage that reduces the spacing between myosin and actin filaments. The model shows that more sarcoplasm is expelled from the shortened sarcomeres after the rigor development. 


\section{Biochemical aspects}

In addition to the aforementioned factors involved in muscle shortening, other factors of importance for meat quality show interrelationship with sarcomere length.

\subsection{Proteolysis}

If muscle is aged before cooking, it usually becomes more tender due to proteolysis. The proteolytic process and the resultant degree of tenderization are dependent on sarcomere length. Davey et al. (1967) used cold shortened beef sternomandibularis muscle to study meat tenderization at different sarcomere lengths. With an increasing degree of muscle shortening beyond $20 \%$ a progressive decrease occurred in the extent to which the meat tenderized during ageing ( 3 days at $15^{\circ} \mathrm{C}$ ), and tenderization was completely arrested at $40 \%$ shortening. Tenderization is caused by degradation of structural proteins in meat by endogenous proteases. The knowledge of proteolytic enzymes in muscle continues to expand. There is convincing evidence that the calpain proteolytic enzymes are involved in post-mortem proteolysis (Huff-Lonergan, Mitsuhashi, Beekman, Parrish, Olson, \& Robson, 1996; Geesink, Kuchay, Chishti \& Koohmaraie, 2006). The calpain system in relation to meat tenderness has been thoroughly reviewed (Lonergan, Zhang \& Lonergan, 2010; Kemp, Sensky, Bardsley, Buttery \& Parr, 2010; Koohmaraie \& Geesink, 2006). Many studies have suggested that $\mu$ calpain is the most important enzyme in post-mortem proteolysis, however, in porcine muscle activation of $\mathrm{m}$-calpain has been demonstrated (Pomponio, Lametsch, Karlsson, Costa, Grossi \& Ertbjerg, 2008; Pomponio \& Ertbjerg, 2012). Other enzyme systems have been studied and been implicated in catalyzing some proteolytic degradation in postmortem muscle (for review see: Sentandreu, Coulis \& Ouali, 2002). Ouali (1992) considered a synergistic action of both lysosomal enzymes and calpains and later a hypothesis was proposed (Ouali, Herrera-Mendez, Coulis, Becila, Boudjellal, Aubry \& Sentandreu, 2006) that several enzymes including caspases are related to variation in meat tenderness. The involvement of caspases have received experimental support (Kemp et al., 2010) and caspase in chicken was shown to be able to reproduce the degradation pattern of titin, nebulin and $\alpha$-actinin during meat ageing (Huang, Huang, Xue, Xu \& Zhou, 2011). Enzymes such as serine peptidases and the proteasome have been related to postmortem proteolysis by studying effects of protease inhibitors. The concentration of serine peptidase inhibitors in beef is thus a relative good predictor of meat tenderness (Zamora, Debiton, Lepetit, Dransfield, Lebert \& Ouali, 1996; Zamora, Aubry, Sayd, Lepetit, Lebert, Sentandreu \& Ouali, 2005). $\mu$-Calpain and the proteasome have been studied using inhibitors against the enzyme activities and it was shown that inhibition of proteasome activity prevented degradation of proteins like troponin-T and nebulin (Houbak, Ertbjerg \& Therkildsen, 2008). Although the calpain system should be considered to be mainly responsible for texture development in meat, an increasing number of proteases have been implicated in making a contribution to postmortem proteolysis, thereby supporting the view that postmortem protein degradation is multi-enzymatic in nature. 
The lack of ageing of $40 \%$ shortened meat described by Davey et al. (1967) could suggest that increased overlap of myosin and actin filaments reduces the availability of proteolytically susceptible sites. The relationship between sarcomere length and proteolysis has been addressed in few studies and conflicting results were obtained. Wheeler \& Koohmaraie (1999) found no effect of sarcomere length on degradation of desmin and troponin-T in lamb longissimus and psoas major muscles and White, O'Sullivan, O'Neill, \& Troy (2006) observed in beef longissimus muscle no clear effect of cold shortening on degradation of troponin-T after a 21 days ageing period.

The effect of sarcomere length on proteolysis has not been investigated in many studies. Shortening was suggested to reduce the accessibility of proteolytic enzymes to the myofibrillar proteins (Iversen, Henckel, Larsen, Monllao, \& Møller, 1995). Weaver, Bowker and Gerrard (2009) observed that proteolysis of troponin-T occurred faster at long sarcomere lengths following incubation of bovine myofibrils with $\mu$-calpain. In agreement, proteolysis of titin was observed to occur faster in bovine muscles with longer sarcomere lengths (England, Fisher, Wells, Mohrhauser, Gerrard, \& Weaver, 2012).

\subsection{Glycogen metabolism}

\section{Rate of $\mathrm{pH}$ decrease}

From the previous sections it is evident that the $\mathrm{pH}$ - temperature combinations at the onset of rigor are of importance for the degree of shortening and meat tenderness. Once the $\mathrm{pH}$ of the muscle has fallen below around $\mathrm{pH} \mathrm{6.0,} \mathrm{the} \mathrm{tendency} \mathrm{for} \mathrm{the} \mathrm{muscle} \mathrm{to} \mathrm{cold} \mathrm{shorten} \mathrm{is}$ reduced. For beef it is has been suggested that the temperature should not fall below $10^{\circ} \mathrm{C}$ while the $\mathrm{pH}$ is higher than 6.2. Hannula \& Puolanne (2004) recommended that for beef longissimus muscle the $\mathrm{pH}$ must fall below 5.7 before the temperature reaches $7{ }^{\circ} \mathrm{C}$.

For muscles on the carcass the relationship between shortening and meat toughness is more complex than that observed in Fig. 6. for pre-rigor excised muscles. Especially the slow glycolysing muscles on the carcass have an increased risk of toughness due to cold shortening. Møller \& Vestergaard (1987) divided pork carcasses into two groups based upon pH value of longissimus muscle at $45 \mathrm{~min}$ post-mortem. They found a highly significant negative correlation between shear force value and sarcomere length in slow glycolysing muscles and no correlation in fast glycolysing muscles. Very similar results were obtained on beef longissimus muscle by Smulders, Marsh, Swartz, Russell \& Hoenecke (1990) who used pH at 3 hours to differentiate between fast and relatively slow glycolysis rates. The correlation between panel assessed tenderness and sarcomere length of unaged meat was very high in slow glycolysers ( $r=0.84$, Fig. 11a) but negligible in those of faster $\mathrm{pH}$ decline (Fig. 11b). Although the underlying reason for these results still remains to be elucidated, the practical 
implication is that an accelerated glycolytic rate and rigor onset can be desirable for tenderness improvement.

(a)

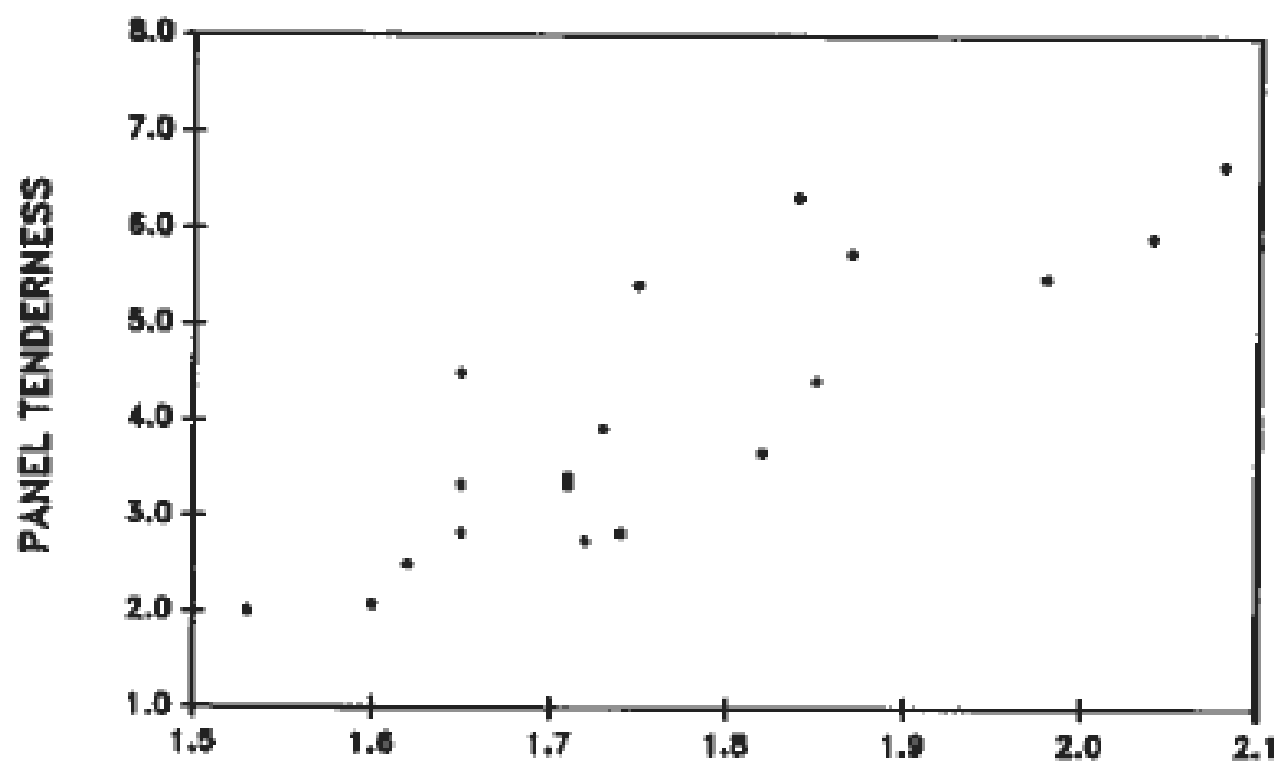

(b)

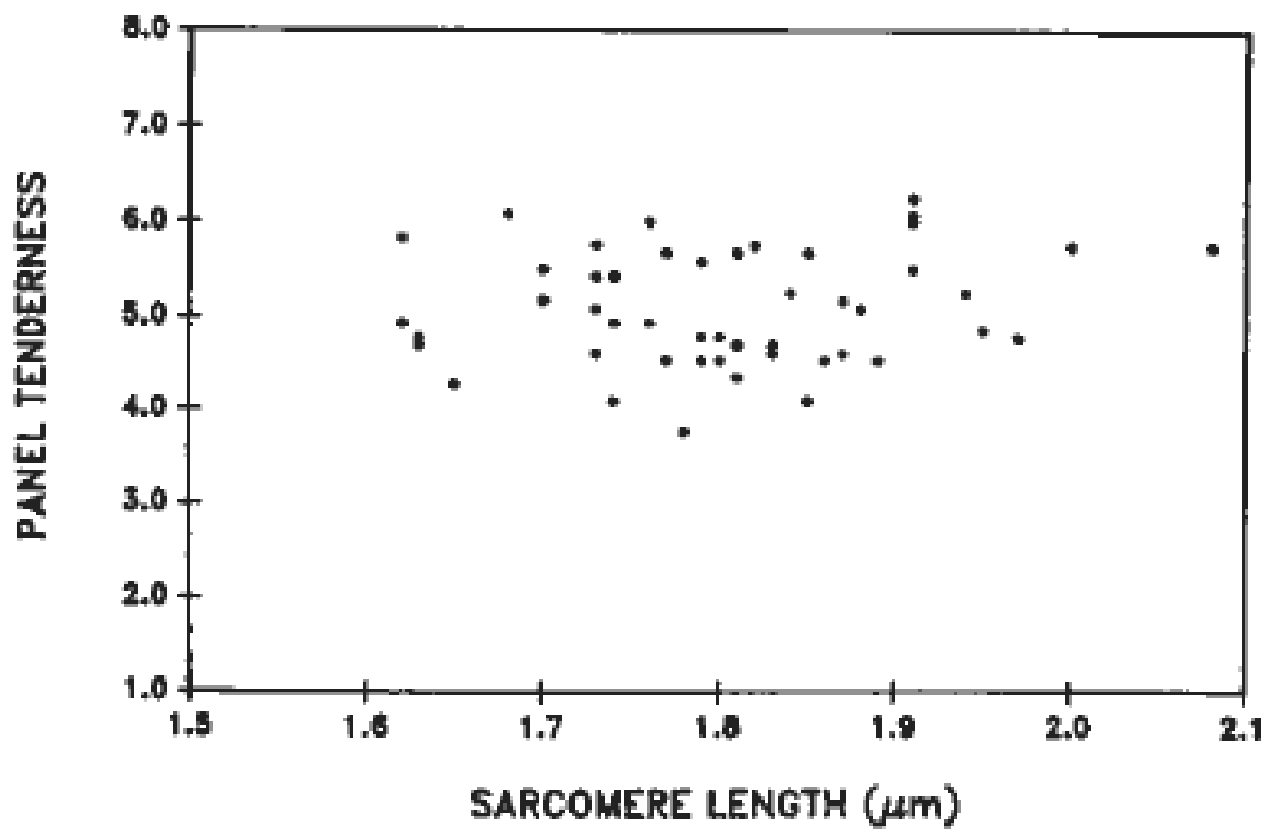

Fig. 11. Consumer panel tenderness scores of bovine longissimus steaks at $\mathbf{4 8}$ hours postmortem in relation to sarcomere length after grouping based on $\mathbf{p H}$ at $\mathbf{3}$ hours $\left(\mathrm{pH}_{3}\right)$. (a) $\mathrm{pH}_{3}>6.3$ (ranging from 6.33 to 6.78): $r=0.84, P<0.001$. (b) $\mathrm{pH}_{3}<6.3$ (ranging from 5.40 to 6.27): $r=0.16, P>0.1$. From Smulders, Marsh, Swartz, Russell and Hoenecke (1990). 


\section{Ultimate $\mathrm{pH}$}

The toughness of beef was reported to increase with a rise in ultimate $\mathrm{pH}$ from 5.5 to around 6.0, and then to decrease with further rise in pH up to 7.0 (Puolanne, 1988; Purchas, 1990; Watanabe, Daly \& Devine, 1996), and similar data has also been reported for pork (Dransfield, Nute, Mottram, Rowan \& Lawrence, 1985). The curvilinear relationship between ultimate $\mathrm{pH}$ and shear force is illustrated in Fig. 12 (upper part). As the pH in beef increases from 5.5 to 6.2 there is a decrease in sarcomere length (Fig. 12, lower part), which partially may explain the increase in toughness of intermediate pH meat (Purchas, 1990; Purchas \& Aungsupakorn, 1993).
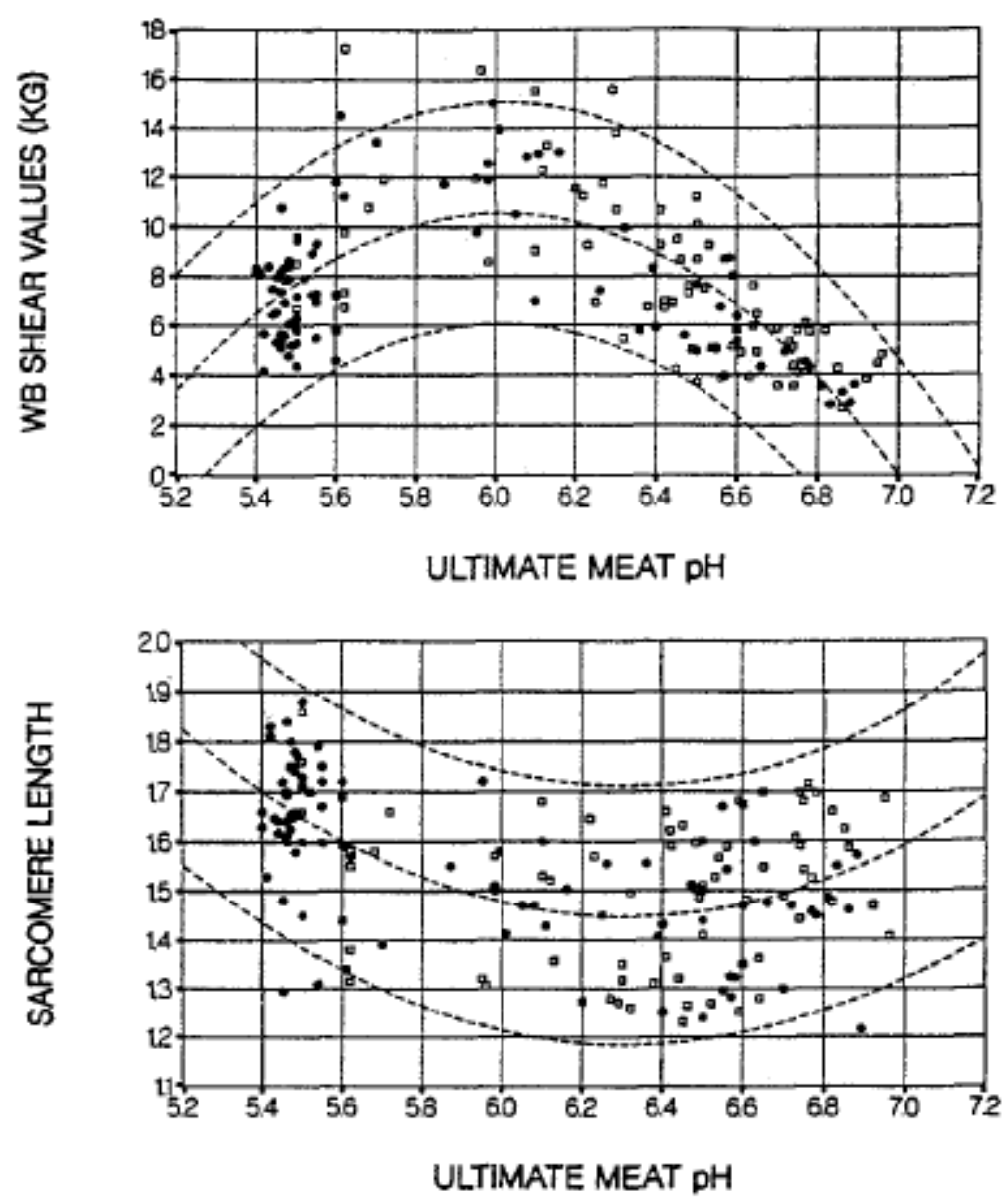

Fig. 12. Relationship between ultimate pH and Warner-Bratzler shear force (upper graph) and sarcomere length (lower graph). The figure was drawn based on values for 80 bulls ( $\square$ ) and 80 steers $(\bullet)$. The quadratic regression lines and the $95 \%$ confidence limits for prediction are shown. From Purchas (1990).

Additionally, the effect of proteolysis should be considered as the activity of proteolytic enzymes in meat is greatly affected by ultimate $\mathrm{pH}$. Intermediate $\mathrm{pH}$ beef longissimus showed only small degradation of Z-lines compared to muscle with high or low ultimate $\mathrm{pH}(\mathrm{Yu}$ and 
Lee, 1986), suggesting the involvement of different proteolytic enzyme systems at high and low ultimate $\mathrm{pH}$. Penny \& Ferguson-Pryce (1979) measured the degradation of troponin-T in beef muscle homogenates at different $\mathrm{pH}$ values. At high $\mathrm{pH}$ (above 6.0) troponin-T degradation was accelerated by $\mathrm{Ca}^{2+}$ ions. At low $\mathrm{pH}$ troponin-T was degraded by $\mathrm{Ca}^{2+}$ independent enzymes, indicating that different enzymes were involved in proteolysis at high and low $\mathrm{pH}$. In pork longissimus the proteolytic degradation pattern of myofibrillar proteins in meat with normal ultimate $\mathrm{pH}$ of 5.66 were compared to a high ultimate $\mathrm{pH}$ of 6.44 (Ertbjerg, Henckel, Karlsson, Larsen \& Møller, 1999). Marked differences in the degradation pattern of troponin-T, troponin-I and vinculin were observed along with greater $\mu$-calpain activity at high ultimate $\mathrm{pH}$ and greater soluble and myofibril-bound cathepsin B and L activity at normal ultimate $\mathrm{pH}$. The decreased toughness as ultimate $\mathrm{pH}$ increases above 6.0 is not clearly related to the sarcomere length. However, it can be explained by a combination of increased water-holding capacity and greater activity of proteases such as calpains (Ertbjerg et al., 1999; Lomiwes, Farouk, Wiklund, \& Young, 2014) and the proteasome (Dutaud, Aubry, Guignot, Vignon, Monin \& Ouali, 2006; Houbak, Ertbjerg \& Therkildsen, 2008).

\section{Technological aspects}

\subsection{Prevention of sarcomere shortening in meat: mechanical stretching}

In practice, different approaches exist to avoid the damage to eating quality from sarcomere shortening. One solution is to cool rapidly enough to avoid heat shortening and at the same time to ensure that rigor is nearly completed before cooling to the temperature region that induces cold shortening. Completion of rigor before cooling to the temperature region for cold shortening can be obtained by removal of ATP either by use of delayed chilling (for review on carcass cooling see Savell, Mueller, \& Baird, 2005) or by electrical stimulation (for reviews see Chrystall \& Devine, 1985; Hwang, Devine, \& Hopkins, 2003; Simmons, Daly, Cummings, Morgan, Johnson, \& Lombard, 2008). Electrical stimulation is commonly used for beef and lamb carcasses. It accelerates glycolysis rate and the onset of rigor and thereby protects the muscles when exposed to chilling conditions which might otherwise cause cold shortening.

Another approach to prevent short sarcomere lengths is to physically restrain the muscles from shortening. The extent of shortening of muscles in the carcass depends on the physical restriction imposed by the attachment to the skeleton of the animal. When carcasses are hung by the Achilles tendon, the hind leg is pulled backward, which will result in less skeletal restraint on many hind limb muscles and on muscles along the vertebral column, thereby permitting more shortening of these muscles during rigor. Herring, Cassens, \& Briskey (1965b) compared vertically suspended beef carcass sides (Achilles hung) to horizontally placed sides. The sarcomere length of muscles from Achilles hung carcasses varied from 3.6 to $1.8 \mu \mathrm{m}$, while muscles from horizontally placed sides showed much reduced variation and varied from 2.7 to $2.0 \mu \mathrm{m}$. Muscles which were lengthened due to the horizontal position were 
longissimus dorsi, gluteus medius, adductor, biceps femoris, and semitendinosus and all of these muscles were more tender. Toughening due to cold and heat shortening can be prevented in lamb if carcasses enter rigor mortis in a standing position (Davey \& Gilbert, 1973). The shortening during rigor can in practice be reduced by suspension of carcasses in the aitchbone, whereby the hind leg hangs more horizontally. This hanging method is known as hip suspension, pelvic suspension and Tender-Stretch. Pelvic suspension results in a more natural position of the muscles in relation to the skeleton, and leads to longer sarcomeres and more tender meat in some of the larger muscles in the round and the loin of beef (Ahnström, Hunt \& Lundström, 2012; Hostetler, Landmann, Link \& Fitzhugh, 1970; Sørheim, Idland, Halvorsen, Frøystein, Lea \& Hildrum, 2001)). Pelvic suspension also effectively increases the sarcomere length and reduces the shear force values of some muscles in other species such as longissimus of pork (Møller \& Vestergaard, 1986) and semimembranosus of lamb (Kim, Kerr, Geesink \& Warner, 2014) and alpaca (Smith, Bush, van de Ven \& Hopkins, 2017). The disadvantages in terms of increased labor to rehang carcasses and a slightly decreased chiller capacity are a small price to pay for the increased palatability (Thompson, 2002).

\subsection{Cooking}

When meat is cooked post-rigor there is a progressive decrease in sarcomere length with increasing cooking temperature (Eikelenboom, Barnier, Hoving-Bolink, Smulders, \& Culioli, 1998). Cooking meat before onset of rigor can induce a strong muscle contraction. Cooking beef triceps brachii muscle pre-rigor at a heating rate of $1^{\circ} \mathrm{C}$ per min was found to produce a more pronounced shortening with a sarcomere length of $1.30 \mu \mathrm{m}$ compared to a six times slower heating rate resulting in a sarcomere length of $1.70 \mu \mathrm{m}$ (Abugroun, Forrest, Aberle \& Judge, 1985). Cooking of lamb longissimus muscle pre-rigor, rigor and post-rigor resulted in large differences in the contraction status of the meat after cooking (Geesink, Sujang \& Koomaraie, 2011). Severe muscle contraction occurred during cooking of pre-rigor and atrigor meat, resulting in sarcomere lengths ranging from 1.05 to $1.20 \mu \mathrm{m}$, whereas the postrigor samples had a mean sarcomere length of $1.44 \mu \mathrm{m}$ after cooking.

Rapidly cooked pre-rigor muscle has been related to increased meat tenderness, and is reported to be produced by tearing and cracking of the muscle structure as a result of the pronounced shortening during cooking. Cia \& Marsh (1976) argued that the increased tenderness of rapidly cooked pre-rigor meat was a consequence of rupture of structures in the fiber in some areas induced by extreme shortening in other areas. Each cross bridge formed between myosin and actin filaments will contribute to the force generated by the muscle during the heat-induced shortening, and the more cross bridges formed per time unit, the greater the force generated. At shortening greater than $40 \%$, the force will be sufficient to crack and shear the muscle structure (Marsh et al., 1974). 
Lepetit, Grajales, and Favier (2000) studied normal and shortened beef samples to explain why cold shortened meat is so tough and exudative. They found that normal samples had higher breaking stress at $50{ }^{\circ} \mathrm{C}$ than contracted. The stress decreased at $55^{\circ} \mathrm{C}$, but a similar decrease was not found in contracted samples. Above $60^{\circ} \mathrm{C}$ the sarcomere length decreased irrespective of the original length. The contracted samples become tougher above $60^{\circ} \mathrm{C}$. Drip and cooking losses were highest in contracted muscles. It was suggested that the differences depend on the shrinkage of collagen that takes place differently in normal and contracted muscles.

\subsection{Water-holding capacity in meat products}

Information on the relationship between sarcomere length and water-holding in processed meats is limited. Nagy-Németh and Vada-Kovács (1979) studied pork with normal sarcomere length and pork that had been contracted using added ATP. Sarcomere lengths were not given, though. In pH 5.9 and $0.6 \mathrm{M} \mathrm{KCl}$ and four hours at temperatures 4,25 and $37{ }^{\circ} \mathrm{C}$ the extractability of myofibrillar proteins without phosphate was about 37,35 and $14 \%$ and with phosphate 33, 32 and $25 \%$, respectively. In contracted meat the values were about 19, 19 and $14 \%$ without phosphate and 25, 29 and $14 \%$ with phosphate, i.e. markedly lower, especially without phosphate. Another interesting feature was that meat kept at $37{ }^{\circ} \mathrm{C}$ showed low values irrespective of the treatments. Later Vada-Kovács (1994) found that in porcine longissimus dorsi muscle the swelling is not influenced by stretching, but the extractability of myofibrillar proteins was higher in stretched muscle after pre-rigor incubation at 4 and $15^{\circ} \mathrm{C}$ but lower when incubated at $36^{\circ} \mathrm{C}$. This suggests that the extraction of myosin will be greater when the myosin is more readily accessible, i.e. not being bound to actin. On the contrary, however, Offer and Trinick (1983) did not find any marked differences in extractability and swelling in salt solutions when the sarcomere lengths were 2.1 or $2.9 \mu \mathrm{m}$. The extractability of myofibrillar proteins is relevant especially in curing of larger meat particles. From the results it can be anticipated that the sarcomere length is a relevant factor in relation to water-holding (and fat-holding), i.e. to the stability of cooked gels.

Puolanne and Halonen (2010) suggested that reason for the effect on chloride salts on waterholding could be that the chaotropic ("hydrophobic") chloride ions penetrate into the hydrophobic core of the myosin filament shaft thus making the filament more negatively charged, which would then cause a swelling of the shaft. This has been shown by Offer and Trinick (1983) who also showed that the swelling of the filament starts at both ends of the filament, which can be taken as an indirect proof for the hypothesis of Puolanne and Halonen (2010) about chaotropic chloride ions penetrating into the core of the myosin shaft. Altogether, this may also explain why the amount of extracted protein is lower from contracted sarcomeres, as the actomyosin bonds hinders the solubilization. This however, does not necessarily mean a lower overall water-holding, as also the actomyosin in situ holds water. The considerations above show that there is still much to study on this topic. 
Within finely comminuted products these aspects may be different. Willems and Purslow (1997) found that the sarcomere lengths increased when pork muscle fibers were stretched $0.5 \mathrm{~d}$ and $7 \mathrm{~d}$ post mortem. The study did not clearly state whether the sarcomere lengths were increased, or the increase was due to fractures in rigor meat that were also seen in the micrographs. The fractures were seen in individual fibers, and in groups of fibers the fracture was at the same line in several fibers, especially in aged samples. Puolanne (1999) calculated an estimate of what would happen in bowl chopper when the knives pass the batter with a high speed of $>100 \mathrm{~m} / \mathrm{s}$. The sharp edge width of a chopper knife is about $25 \mu \mathrm{m}$. With usual chopping procedure ( 6 knives rotating 3000 rounds per minute for 8 minutes) this means that, theoretically, the sharp edge of a chopper knife hits once each part of the batter. The hit is, however, on microscopic level more like mashing than cutting, as the sharp edge of the knife is about 10 sarcomere lengths. Therefore, it can be anticipated that the sarcomeres are stretched and smashed during the chopping which will then result in a better extraction of myofibrillar proteins. The forces prevailing during chopping are much larger than the breaking stresses presented by Willems and Purslow (1997), so the original sarcomere length has no bearing. However, as chopping is a random process at microscopic level, there are, in addition to solubilized proteins, still also myofibril fractions left in a finely chopped batter (Hamm, 1972).

\section{Conclusions}

Studies on the effect of muscle shortening and hence the sarcomere length on meat began almost a century ago. The basic structure of the sarcomere has been known for decades as well as a thorough understanding on the mechanisms behind shortening of the sarcomere during rigor development, thawing of frozen meat and cooling of carcasses. The sarcomere length is known to have a profound effect on basic meat quality traits and especially tenderness and water-holding capacity. The underlying mechanisms are complex and continue to be discussed in the literature.

\section{References}

Abugroun, H.A., Forrest, J.C., Aberle, E.D., \& Judge, M.D. (1985). Shortening and tenderness of pre-rigor heated beef: Part 1 - effect of heating rate on muscles of youthful and mature carcasses. Meat Science, 14, 1-13.

Agarkova, I., \& Perriard, J.C. (2005). The M-band: an elastic web that crosslinks thick filaments in the center of the sarcomere. Trends in Cell Biology, 15, 477-485. 
Ahnström, M.L., Hunt, M.C., \& Lundström, K. (2012). Effect of pelvic suspension of beef carcasses on quality and physical traits of five muscles from four gender-age groups. Meat Science, 90, 528-535.

Bate-Smith, E. C. (1939). Changes in elasticity of mammalian muscle undergoing rigor mortis. Journal of Physiology, 96, 179-193.

Bate-Smith, E.C., \& Bendall, J.R. (1947). Rigor mortis and adenosine triphosphate. Journal of Physiology, 106, 177-185.

Bate-Smith, E. C., \& Bendall, J.R. (1949). Factors determining the time course of rigor mortis. Journal of Physiology, 110, 47-65.

Behnke, J.R., Fennema, O., \& Cassens, R.G. (1973) Rates of postmortem metabolism in frozen animal tissues. Journal of Agricultural and Food Chemistry, 21, 5-11.

Bendall, J.R. (1951). The shortening of rabbit muscles during rigor mortis: its relation to the breakdown of adenosine triphosphate and creatine phosphate and to muscle contraction. Journal of Physiology, 114, 71-88.

Bendall, J.R. (1975). Cold-contracture and ATP-turnover in the red and white musculature of the pig, post mortem. Journal of the Science of Food and Agriculture, 26, 55-71.

Bendall, J.R., Voyle, C.A. (1967) Study of the histological changes in the growing muscles of beef animals. Journal of Food Technology, 2, 259-283.

Bertram, H.C., Purslow, P.P., \& Andersen, H.J. (2002). Relationship between meat structure, water mobility, and distribution: A low-field nuclear magnetic resonance study. Journal of Agricultural and Food Chemistry, 50, 824-829.

Borbiro M., \& Szent-Györgyi, A. (1949). On the relation between tension and ATP in crossstriated muscle. Biological Bulletin Woods Hole, 96, 162-167.

Bouton, P.E., Harris, P.V., \& Shorthose, W.R. (1972). The effects of ultimate pH on ovine muscle: Water-holding capacity. Journal of Food Science, 37, 351-355.

Buege, D.R., \& Marsh, B.B. (1975). Mitochondrial calcium and postmortem muscle shortening. Biochemical and Biophysical Research Communications, 65, 478-482.

Castillo, A., Nowak, R., Littlefield, K. P., Velia M. Fowler, V.M., \& Littlefield, R.S. (2009). Nebulin ruler does not dictate thin filament lengths. Biophys J. 96, 1856-1.Chrystall, B.B., \& Devine, C.E. (1985). Electrical stimulation: Its early development in New Zealand. In: A.M. Pearson \& T.R. Dutson (Ed.) Advances in Meat Research. Vol. 1. Electrical Stimulation. pp 73-119. AVI Publishing Co., Westport, Connecticut. 
Cia, G., \& Marsh, B.B. (1976). Properties of beef cooked before rigor onset. Journal of Food Science, 41, 1259-1262.

Cook, C.F., \& Langsworth, R.F. (1966). The effect of pre-slaughter environmental temperature and post-mortem treatment upon some characteristics of ovine muscle. I. Shortening and $\mathrm{pH}$. Journal of Food Science, 31, 497-503.

Cornforth, D. P., Pearson, A.M., \& Merkel, R.A. (1980). Relationship of mitochondria and sarcoplasmic reticulum to cold shortening. Meat Science, 4, 103-121.

Davey, C.L., \& Gilbert, K.V. (1973). The effect of carcass posture on cold, heat and thaw shortening in lamb. Journal of Food Technology, 8, 445-451.

Davey, C.L., \& Gilbert, K.V. (1975). The tenderness of cooked and raw meat from young and old animals. Journal of the Science of Food and Agriculture, 26, 953-960.

Davey, C.L., Kuttel, H., \& Gilbert, K.V. (1967). Shortening as a factor in meat ageing. Journal of Food Technology, 2, 53-56.

Diesbourg, L., Swatland, H. J., \& Millman, B. M. (1988). X-ray diffraction measurements of postmortem changes in the myofillament lattice of pork. Journal of Animal Science, 66, 10481054.

Dransfield, E., \& Lokyer, D.K. (1985). Cold-shortening toughness in excised pork $M$. longissimus dorsi. Meat Science, 13, 19-32.

Dransfield, E., Nute, G.R., Mottram, D.S., Rowan, T.G., \& Lawrence, T.L.J. (1985). Pork quality from pigs fed on low glucosinate rapeseed meal: Influence of level in the diet, sex and ultimate $\mathrm{pH}$. Journal of the Science of Food and Agriculture, 36, 546-556.

Dutaud, D., Aubry, L., Guignot, F., Vignon, X., Monin, G., \& Ouali, A. (2006). Bovine muscle $20 \mathrm{~S}$ proteasome. II: Contribution of the $20 \mathrm{~S}$ proteasome to meat tenderization as revealed by an ultrastructural approach. Meat Science 74, 337-344.

Eikelenboom, G., Barnier, V.M.H., Hoving-Bolink, A.H., Smulders, F.J.M., \& Culioli, J. (1998). Effect of pelvic suspension and cooking temperature on the tenderness of electrically stimulated and aged beef, assessed with shear and compression tests. Meat Science, 49, 8999.

Elliott, G.F., Lowy, J., \& Millman, B.M. (1967). Low-angle X-ray diffraction studies of living striated muscles during contraction. Journal of Molecular Biology, 25, 31-45.

Elliott, G.F., Lowy, F.J., \& Worthington, C.R. (1963). An X-ray and light diffraction study of the filament lattice of striated muscle in the living state and in rigor. Journal of Molecular Biology, 6, 295-305. 
England, E.M., Fischer, K.D., Wells, S.J., Mohrhauser, D.A., Gerrard, D.E., Weaver, A.D. (2012) Postmortem titin proteolysis is influenced by sarcomere length in bovine muscle. Journal of Animal Science, 90, 989-995.

Ertbjerg, P., Henckel, P. Karlsson, A., Larsen, L. M., \& Moller, A. J. (1999). Combined effect of epinephrine and exercise on calpain/calpastatin and cathepsin B and L activity in porcine longissimus muscle. Journal of Animal Science, 77, 2428-2436.

Feldhusen, F., \& Kühne, M. (1992. Effects of ultrarapid chilling and ageing on length of sarcomeres, and tenderness of pork. Meat Science, 32, 161-171.

Fischer, C., Honikel, K.O., \& Hamm, R. (1980). Über das Auftreten der Kälteverkürzung ("Cold shortening") in dunkler und heller Muskulatur bei Rind und Schwein (Cold shortening in the dark and light musculature of cattle and pigs). Fleischwirtschaft 60, 263-265.

Fritz, J.D., Wolff, J.A., \& Greaser, M.L. (1993). Characterization of a partial cDNA clone encoding porcine skeletal muscle titin: Comparison with rabbit and mouse skeletal muscle titin sequence. Comparative Biochemistry and Physiology, 105B, 357-360.

Galloway, D.E., \& Goll, D.E. (1967). Effect of temperature on molecular properties of postmortem porcine muscle. Journal of Animal Science, 26, 1302-1308.

Geesink, G. H., Kuchay, S. Chishti, A.H., \& Koohmaraie M. (2006). $\mu$-Calpain is essential for postmortem proteolysis of muscle proteins. Journal of Animal Science, 84, 2834-2840.

Geesink, G., Sujang, S., \& Koohmaraie M. (2011). Tenderness of pre- and post rigor lamb longissimus muscle. Meat Science, 88, 723-726.

Geesink, G.H., Taylor, R.G., Bekhit, A.E.D., \& Bickerstaffe, R. (2001). Evidence against the nonenzymatic calcium theory of tenderization. Meat Science, 59, 417-422.

Geeves, M.A., \& Holmes, K.C. (2005). The molecular mechanism of muscle contraction. Advances in Protein Chemistry, 71, 161-193.

Goldspink, G. (1971). Changes in striated muscle fibres during contraction and growth with particular reference to myofibril splitting. Journal of Cell Science 9, 123-137.

Gothard, R.H., Mullins, A.M., Boulware, R.F., \& Hansard, S.L. (1966). Histological studies of post-mortem changes in sarcomere length as related to bovine muscle tenderness. Journal of Food Science, 31, 825-828.

Hamm, R. (1972). Kolloidchemie des Fleisches. Berlin and Hamburg: Paul Parey.

Hannula, T., \& Puolanne, E. (2004). The effect of cooling rate on beef tenderness: The significance of $\mathrm{pH}$ at $7^{\circ} \mathrm{C}$. Meat Science, $67,403-408$. 
Haselgrove, J.C., \& Huxley, H.E. (1973). X-ray evidence for radial cross-bridge movement and for sliding filament model in actively contacting skeletal muscle. Journal of Molecular Biology, 77, 549-568.

Herring, H.K., Cassens, R.G., \& Briskey, E.J. (1965a). Sarcomere length of free and restrained bovine muscles at low temperatures as related to tenderness. Journal of Science of Food and Agriculture, 16, 379-384.

Herring, H.K., Cassens, R.G., \& Briskey, E.J. (1965b). Further studies on bovine muscle tenderness as influenced by carcass position, sarcomere length, and fiber diameter. Journal of Food Science, 30, 1049-1054.

Herring, H.K., Cassens, R.G., Suess, C.G., Brungardt, V.H., \& Briskey, EJ. (1967). Tenderness and associated characteristics of stretched and contracted bovine muscles. Journal of Food Science, 32, 317-323.

Honikel, K.O., \& Hamm, R. (1978). Influence of cooling and freezing of minced pre-rigor muscle on the breakdown of ATP and glycogen. Meat Science, 2, 181-188.

Honikel, K.O., Kim, C.J., Hamm, R., \& Roncales, P. (1986). Sarcomere shortening of prerigor muscles and its influence on drip loss. Meat Science, 16, 267-282.

Hopkins, D.L., \& Thompson, J.M. (2001). Inhibition of protease activity 2. Degradation of myofibrillar proteins, myofibril examination and determination of free calcium levels. Meat Science, 59, 199-209.

Hostetler, R.L., Landmann, W.A., Link B.A., \& Fitzhugh, H.A., Jr. (1970). Influence of carcass position during rigor mortis on tenderness of beef muscles: Comparison of two treatments. Journal of Animal Science, 31, 47-50.

Houbak, M.B., Ertbjerg, P., \& Therkildsen, M. (2008). In vitro study to evaluate the degradation of bovine muscle proteins post-mortem by proteasome and $\mu$-calpain. Meat Science, 79, 77-85.

Huang, M., Huang, F., Xue, M., Xu, X., \& Zhou, G. (2011). The effect of active caspase-3 on degradation of chicken myofibrillar proteins and structure of myofibrils. Food Chemistry, 128, 22-27.

Huff-Lonergan, E., Mitsuhashi, T., Beekman, D.D., Parrish, F.C., Olson, D.G., \& Robson, R. M. (1996). Proteolysis of specific muscle structural proteins by $\mu$-calpain at low $\mathrm{pH}$ and temperature is similar to degradation in postmortem bovine muscle. Journal of Animal Science, 74, 993-1008.

Hughes, J.M., Oiseth, S.K., Purslow, P.P., \& Warner, R.D. (2014) A structural approach to understanding the interactions between colour, water-holding capacity and tenderness. Meat Science, 98, 520-532. 
Huxley, H.E. (1963). Electron microscope studies on the structure of natural and synthetic protein filaments from striated muscle. Journal of Molecular Biology, 7, 281-308.

Huxley, H.E. (1969). The mechanism of muscular contraction. Science, 164, 1356-1366.

Huxley, H.E., \& Brown, W. (1967). The low-angle X-ray diagram of vertebrate striated muscle and its behavior during contraction and rigor. Journal of Molecular Biology, 30, 383-434.

Huxley, A.F., \& Simmons, R.M. (1971) Proposed mechanism of force generation in striated muscle. Nature, 133, 533-538.

Hwang, I.H., Devine, C.E., \& Hopkins, D.L. (2003). The biochemical and physical effects of electrical stimulation on beef and sheep meat tenderness. Meat Science, 65, 677-691.

Irving, T.C., Swatland H.J., \& Millman B.M. (1989). X-ray diffraction measurements of myofilament lattice spacing and optical measurements of reflectance and sarcomere length in commercial pork loins. Journal of Animal Science, 67, 152-156.

Iversen, P., Henckel, P., Larsen, L.M., Monllao, S., \& Møller, A.J. (1995). Tenderisation of pork as affected by degree of cold-induced shortening. Meat Science, 40, 171-181.

Jahromi, S.S. \& Charlton, P. (1979). Transverse sarcomere splitting. Journal of Cell Biology, 80, 736-742.

Jeacocke, R.E. (1984). The kinetics of rigor onset in beef muscle fibers. Meat Science, 11, 237251.

Jeacocke, R.E. (1993). The concentrations of free magnesium and free calcium ions both increase in skeletal muscle fibres entering rigor mortis. Meat Science, 35, 27-45.

Ji, J.-R., \& Takahashi, K. (2006). Changes in concentration of sarcoplasmic free calcium during post-mortem ageing of meat. Meat Science 73, 395-403.

Kemp, C.M., Sensky, P.L., Bardsley, R.G., Buttery, P.J., \& Parr, T. (2010). Tenderness - An enzymatic view. Meat Science, 84, 248-256.

Kim, Y.H.B., Kerr, M., Geesink, G., \& Warner, R.D. (2014) Impacts of hanging method and high pre-rigor temperature and duration on quality attributes of ovine muscles. Animal Production Science, 54, 414-421.

Kontrogianni-Konstantopoulos, A., Ackermann, M. A., Bowman, A.L., Yap, S.V., \& Bloch, R.J. (2009). Muscle giants: Molecular scaffolds in sarcomerogenisis. Physiological Reviews, 89, 1217-1267.

Koohmaraie, M., Doumit, M.E., \& Wheeler, T.L. (1996). Meat toughening does not occur when rigor shortening is prevented. Journal of Animal Science, 74, 2935-2942. 
Koohmaraie, M., \& Geesink, G.H. (2006). Contribution of postmortem muscle biochemistry to the delivery of consistent meat quality with particular focus on the calpain system. Meat Science, 74, 34-43.

Kushmerick, M.J., \& Davies, R.D. (1968). The role of phosphate compounds in thaw contraction and the mechanism of thaw rigor. Biochimica et Biophysica Acta, 153, 279-287.

Kuttappan, V.A., Hargis, B.M., \& Owens, C.M. (2016). White striping and woody breast myopathies in modern poultry industry: a review. Poultry Science, 95, 2724-2733.

Lepetit, J., Grajales, A., \& Favier, R. (2000). Modelling the effect of sarcomere length on collagen shortening in cooked meat: consequence on meat toughness. Meat Science, 54, 239250.

Linari, M., Dobbie, I., Reconditi, M., Koubassova, N., Irving, M., Piazzesi, G., \& Lombardi, V. (1998) The stiffness of skeletal muscle in isometric contraction and rigor: The fraction of myosin heads bound to actin. Biophysical Journal, 74, 2459-2473.

Lindstedt, S., \& Nishikawa, K. (2017). Huxleys missing filament: Form and function of titin in vertebrate striated muscle. Annual Review of Physiology, 79, 145-466.

Liu, J., Arner, A., Puolanne, E., \& Ertbjerg, P. (2016). On the water-holding of myofibrils: Effect of sarcoplasmic protein denaturation. Meat Science, 119, 32-40.

Locker, R. H. (1959). Striation patterns of ox muscle in rigor mortis. Journal of Biophysical and Biochemical Cytology, 6, 419-422.

Locker, R.H. (1960). Degree of muscular contraction as a factor in the tenderness of beef. Food Research, 25, 304-307.

Locker, R.H. (1985). Cold-induced toughness of meat. In: A.M. Pearson \& T.R. Dutson (Ed.) Advances in Meat Research. Vol. 1. Electrical Stimulation. pp 1-44. AVI Publishing Co., Westport, Connecticut.

Locker, R.H., \& Hagyard, C. J. (1963). A cold shortening effect in beef muscle. Journal of the Science of Food and Agriculture 14, 787-793.

Lomiwes, D., Farouk, M.M., Wiklund, W., \& Young, O.A. (2014). Small heat shock proteins and their role in meat tenderness: A review. Meat Science, 96, 26-40.

Lonergan, E.H., Zhang, W., \& Lonergan, S.M. (2010). Biochemistry of postmortem muscle Lessons on mechanisms of meat tenderization. Meat Science 86, 184-195.

Long, L., Zhang, J, Wang, Y., \& Luo, P. (2010). The tension-stress effects on growth of the external sphinchter: Animal experiment and its application on treatment of anorectal stenosis. Chinese Medical Journal, 110, 325-331. 
Lundsgaard, E. (1950). The ATP content of resting and active muscle. Proceedings of the Royal Society London B, 137, 73-76.

Marsh, B.B. (1954). Rigor mortis in beef. Journal of the Science of Food and Agriculture, 5, 7075.

Marsh, B.B., \& Carse W.A. (1974). Meat tenderness and the sliding-filament hypothesis. Journal of Food Technology, 9, 129-139.

Marsh, B.B., \& Leet N.G. (1966). Studies in meat tenderness. 3. The effects of cold shortening on tenderness. Journal of Food Science, 31, 450-459.

Marsh, B.B., \& Thompson J.F. (1956). Thaw rigor and the delta state of muscle. Biochimica et Biophysica Acta, 24, 427-428.

Marsh, B. B., \& Thompson J. F. (1958). Rigor mortis and thaw rigor in lamb. Journal of the Science of Food and Agriculture, 9, 417-424.

Marsh, B.B., Leet N.G., \& Dickson, M.R. (1974). The ultrastructure and tenderness of highly cold-shortened muscle. Journal of Food Technology, 9, 141-147.

Marsh, B.B., Woodhams, P.R., \& Leet N.G. (1968). Studies in meat tenderness. 5. Effects on tenderness of carcass cooling and freezing before completion of rigor mortis. Journal of Food Science, 33, 12-18.

Marsh, B.B., Briskey, E.J., Cassens, R.G., \& Kauffman, R.G. (1972). Hot boning and pork tenderness. Journal of Food Science, 37, 179-180.

McCrae, S.E., Seccombe, C.G., Marsh, B.B., \& Carse, W.A. (1971). Studies in meat tenderness. 9. Tenderness of various lamb muscles in relation to their skeletal restraint and delay before freezing. Journal of Food Science, 36, 566-570.

Meyer, L.C., \& Wright, N.T. (2013) Structure of giant muscle proteins. Frontiers in Physiology, 4, 368-380.

Millman, B. M. (1998). The filament lattice of striated muscle. Physiological Review, 78, 359391.

Miroshnichenko, N.S., Balanuk, I.V., \& Nozdrenko, D.N. (2000). Packing of myosin molecules in muscle thick filaments. Cell Biology International, 24, 327-333.

Møller, A.J., \& Vestergaard, T. (1986). Effect of altered carcass suspension during rigor mortis on tenderness of pork loins. Meat Science, 18, 77-87.

Møller, A.J., \& Vestergaard, T. (1987). Effect of delay time before chilling on toughness in pork with high or low initial pH. Meat Science, 19, 27-37. 
Møller, A.J., Kirkegaard, E., \& Vestergaard, T. (1987). Tenderness of pork muscles as influenced by chilling rate and altered carcass suspension. Meat Science, 21, 275-286.

Morgan D.L., Claflin, D.R., \& Julian, F.J. (1991). Tension as a function of sarcomere length and velocity of shortening in single skeletal muscle fibers of the frob. Journal of Physiology, 441, 719-732.

Nagy-Németh, A., \& Vada-Kóvacs, M. 1979. Effect of $\mathrm{pH}$ and temperature on the extractability of myofibrillar proteins. Proc. International Congress of Meat Science and Technology 26, Session 4. 9 p. Available at www.icomst.helsinki.fi.

Offer G. (1991). Modelling the formation of pale, soft and exudative meat: effects of chilling regime and rate and extent of glycolysis. Meat Science 30, 157-184.

Offer G., \& Knight, P. (1988). The structural basis of water-holding in meat. In R. Lawrie (Ed.) Developments in Meat Science - 4, Chapters 3-4, 63-243.

Offer, G. \& Trinick, J. (1983). On the mechanism of water holding in meat: the swelling and shrinking of myofibrils. Meat Science, 8, 245-281.

Ouali, A. (1992.) Proteolytic and physicochemical mechanisms involved in meat texture development. Biochimie, 74, 251-265.

Ouali, A., Herrera-Mendez, C.H., Coulis, G., Becila, S., Boudjellal, A., Aubry L., \& Sentandreu, M.A. (2006). Revisiting the conversion of muscle into meat and the underlying mechanisms. Meat Science, 74, 44-58.

Penny, I.F., \& Ferguson-Pryce, R. (1979). Measurement of autolysis in beef muscle homogenates. Meat Science, 3, 121-134.

Perry, S.V. (1950). Studies on the rigor resulting from the thawing of frozen frog Sartorius muscle. Journal of General Physiology, 33, 563-577.

Pomponio, L., \& Ertbjerg, P. (2012). The effect of temperature on the activity of $\mu$ - and mcalpain and calpastatin during post-mortem storage of porcine longissimus muscle. Meat Science, 91, 50-55.

Pomponio, L., Lametsch, R., Karlsson, A.H., Costa, L.N., Grossi, A., \& Ertbjerg, P. (2008). Evidence for post-mortem m-calpain autolysis in porcine muscle. Meat Science, 80, 761-764.

Puolanne, E. \& Ruusunen, M. (1988). Reducing the incidence of dark-cutting beef in Finland A systematic approach. In: S. U. Fabiansson, W. R. Shorthose \& R.D. Warner (eds). Darkcutting in cattle and sheep. Proceedings of an Australian Workshop (pp. 32-37), AMLRDC, Sydney. 
Puolanne, E., \& Halonen, M. (2010). Theoretical aspects of water-holding in meat. Meat Science, 86, 151-165.

Purchas, R.W. (1990). An assessment of the role of $\mathrm{pH}$ differences in determining the relative tenderness of meat from bulls and steers. Meat Science, 27, 129-140.

Purchas, R.W., \& Aungsupakorn R. (1993). Further investigations into the relationship between ultimate $\mathrm{pH}$ and tenderness for beef samples from bulls and steers. Meat Science, 34, 163-178.

Rassier, D.E. (2012). The mechanisms of the residual force enhancement after stretch of skeletal muscle: non-uniformity in half-sarcomeres and stiffness of titin. Review. Proceedings of Royal Society B, 279, 2705-2713.

Rayment, I., \& Holden, H.M. (1994). Three-dimensional structure of molecular motor. Trends in Biochemical Sciences, 19, 129-134.

Rhodes, D.N., \& Dransfield, E. (1974). Mechanical strength of raw beef from cold-shortened muscles. Journal of the Science of Food and Agriculture, 25, 1163-1164.

Savell, J. W., Mueller, S. L., \& Baird, B. E. (2005). The chilling of carcasses. Meat Science, 70, 449-459.

Schäfer, A., Knight, P.J., Wess, T.J., \& Purslow P.P. (2000). Influence of sarcomere length on the reduction of myofilament lattice spacing post-mortem and its implication on drip loss. In: Proceedings $46^{\text {th }}$ International Congress on Meat Science and Technology, 434-435.

Sentandreu, M.A., Coulis, G., \& Ouali, A. (2002). Role of muscle endopeptidases and their inhibitors in meat tenderness. Trends in Food Science and Technology, 13, 400-421.

Shoichiro, O. (2010). Dynamic regulation of sarcomeric actin filaments in striated muscle. Cytoskeleton (Hoboken), 67(11), 677-692. Published online 2010 Aug 9. doi: 10.1002/cm.20476. PMCID: PMC2963174. NIHMSID: NIHMS-238959.Squire, J., Cantino, M., Chew, M., Denny, R., Harford, J., Hudson, L., \& Luther, P. (1998). Myosin rod-packing schemes in vertebrate muscle thick filaments. Journal of Structural Biology, 122, 128-138.

Sihvo, H-K., Airas, N., Linden, J., \& Puolanne, E. Ultrastructure of wooden breast myopathy in 2-day-old broiler chickens.

Sihvo, H-K., Immonen, K., \& Puolanne, E. (2014). Myodegeneration with fibrosis and regeneration in the pectoralis major muscle of broilers. Veterinary Patology, 51, 619-623.

Simmons, N.J., Daly, C.C., Cummings, T.L., Morgan, S.K., Johnson, N.V., \& Lombard, A. (2008) Reassessing the principles of electrical stimulation. Meat Science, 80, 110-122. 
Smith, M.A., Bush, R.D., van de Ven, R.J., \& Hopkins, D.L. (2017). The combined effect of grain supplementation and tenderstretching on alpaca (Vicugna pacos) meat quality. Meat Science, 125, 53-60.

Smulders, F. J. M., Marsh, B. B., Swartz, D. R., Russell, R. L., \& Hoenecke, M. E. (1990). Beef tenderness and sarcomere length. Meat Science, 28, 349-363.

Squire, J.M. (2009). Muscle myosin filaments: cores, crowns and couplings. Biophysical Reviews, 1, 149-160.

Stromer, M.H., Goll, D.E., \& Roth, L.E. (1967). Morphology of rigor-shortened bovine muscle and the effect of trypsin on pre- and postrigor myofibrils. Journal of Cell Biology, 34, 431-445.

Sørheim, O., Idland, J., Halvorsen, E.C., Frøystein, T., Lea, P., \& Hildrum, K.I. (2001) Influence of beef carcass stretching and chilling rate on tenderness of $\mathrm{M}$. longissimus dorsi. Meat Science, 57, 79-85.

Thompson, J. (2002). Managing meat tenderness. Meat Science, 62, 295-308.

Tskhovrebova, L., \& Trinick, J. (2010). Roles of titin in the structure and elasticity of the sarcomere. Journal of Biomedicine and Biotechnology, Volume 2010, Article ID 612482, 7 pages, doi: 10.1155/2010/612482.

Vada-Kovács, M. (1994). Effect of pre-rigor stretch and various constant temperatures on the rate of postmortem $\mathrm{pH}$ fall, rigor mortis and some quality traits of excised porcine Biceps femoris muscle strips. Meat Science, 42, 49-66.

Voyle, C.A. (1969). Some observations on the histology of cold-shortened muscle. Journal of Food Technology, 4, 275-281.

Watanabe, A., Daly, C.C., \& Devine, C.E. (1996). The effects of the ultimate pH of meat on tenderness changes during ageing. Meat Science, 42, 67-78.

Weaver, A.D., Bowker, B.C., and Gerrard, D.E. (2009) Sarcomere length influences $\mu$-calpainmediated proteolysis of bovine myofibrils. Journal of Animal Science, 87, 2096-2103.

Wheeler, T.L., \& Koohmaraie, M. (1994). Prerigor and postrigor changes in tenderness of ovine longissimus muscle. Journal of Animal Science, 72, 1232-1238.

Wheeler, T.L., Shackelford, S.D., \& Koohmaraie, M. (2000). Variation in proteolysis, sarcomere length, collagen content, and tenderness among major pork muscles. Journal of Animal Science, 78, 958-965.

White, A., O'Sullivan, A., O'Neill, E.E., \& Troy, D.J. (2006). Manipulation of the pre-rigor phase to investigate the significance of proteolysis and sarcomere length in determining tenderness of bovine M. longissimus dorsi. Meat Science, 73, 204-208. 
Willems, M.E.T. \& Purslow, P.P. (1997). Mechanical and structural characteristics of single muscle fibres and fibre groups from raw and cooked pork Longissimus muscle. Meat Science, 46, 285-301.

Williams, P.E., \& Goldspink, G. (1971). Longitudinal growth of striated muscle fibers. Journal of Cell Science, 9, 751-767.

Williams, P.E., \& Goldspink, G. (1978). Changes in sarcomere length and physiological properties in immobilized muscle. Journal of Anatomy, 127, 459-468.

Witt, C.C., Burkart, C., Labeit, D., McNabb, M., Wu, Y., Granzier, H., \& Labeit, S. (2006). Nebulin regulates thin filament length, contractility, and Z-disk structure in vivo. EMBO Journal, 25, 3843-3855.

Wong, G.C.L., Lin, A., Tang, J.X., Li, Y., Janmey, P.A., \& Safinya, C.R. (2003) Lamellar phase of stacked two-dimensional rafts of actin filaments. Physical Review Letters, 91, 018103/1018103/4.

Young, P., Ehler, E., \& Gautel, M. (2001). Obscurin, a giant sarcomeric Rho guanine nucleotide exchange factor protein involved in sarcomere assembly. Journal of Cell Biology, 154, 123-136.

Zamora, F., Aubry, L., Sayd, T., Lepetit, J., Lebert, A., Sentandreu, M. A., \& Ouali, A. (2005). Serine peptidase inhibitors, the best predictor of beef ageing amongst a large set of quantitative variables. Meat Science, 71, 730-742.

Zamora, F., Debiton, E., Lepetit, J., Dransfield, E., Lebert, A., \& Ouali, A. (1996). Predicting variability of ageing and toughness in beef Longissimus muscle. Meat Science, 43, 321-333. 